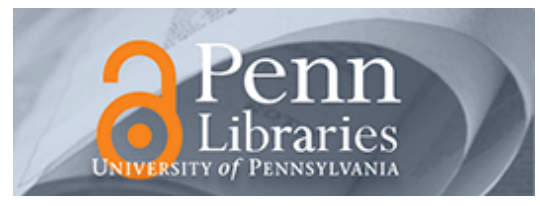

University of Pennsylvania

ScholarlyCommons

Management Papers

Wharton Faculty Research

$12-2014$

\title{
How Do Strategic Factor Markets Respond to Rivalry in the Product Market?
}

Olivier Chatain

University of Pennsylvania

Follow this and additional works at: https://repository.upenn.edu/mgmt_papers

Part of the Business Administration, Management, and Operations Commons

\section{Recommended Citation}

Chatain, O. (2014). How Do Strategic Factor Markets Respond to Rivalry in the Product Market?. Strategic Management Journal, 35 (13), 1952-1971. http://dx.doi.org/10.1002/smj.2188

This paper is posted at ScholarlyCommons. https://repository.upenn.edu/mgmt_papers/31

For more information, please contact repository@pobox.upenn.edu. 


\title{
How Do Strategic Factor Markets Respond to Rivalry in the Product Market?
}

\author{
Abstract \\ This paper explores the interplay between product market, strategic factor market, and resource \\ development. More competition in the product market makes resource buyers bid higher for resources, as \\ the value of trying to preempt the resources is higher. Holding other initial conditions constant, resources \\ are developed more in industries with factor markets than in industries without. When buyers of \\ resources cannot integrate more than one resource, developers choose to develop either at a low or high \\ level, generating a type of heterogeneity that would not arise otherwise. Changes in the intensity of \\ competition in the product market can have the opposite effect on resource development efforts \\ depending on the presence or absence of factor markets.

\section{Keywords} \\ strategic factor markets, resource development, rivalry, product market competition, formal foundations \\ of strategy \\ Disciplines \\ Business Administration, Management, and Operations
}




\title{
How Do Strategic Factor Markets Respond to Rivalry in the Product Market?
}

\author{
Olivier Chatain*
}

July 5, 2013

\begin{abstract}
This paper explores the interplay between product market, strategic factor market and resource development. More competition in the product market makes resource buyers bid higher for resources, as the value of trying to preempt the resources is higher. Holding other initial conditions constant, resources are developed more in industries with factor markets than in industries without. When buyers of resources cannot integrate more than one resource, developers choose to develop either at a low or high level, generating a type of heterogeneity that would not arise otherwise. Changes in the intensity of competition in the product market can have opposite effect on resource development efforts depending on the presence or absence of factor markets.
\end{abstract}

Keywords: Strategic factor markets, Resource development, Rivalry, Product market competition, Formal foundations of strategy

*Management Department, The Wharton School, U. of Pennsylvania. E-mail: chatain@ wharton.upenn.edu. I thank the Editor, two anonymous referees, Tunji Adegbesan, Christian Asmussen, Matthew Bidwell, Laurence Capron, Raj Choudhury, Gary Dushnitsky, Kathy Eisenhardt, Emilie Feldman, Javier Gimeno, Rahul Kapoor, Felipe Monteiro, Evan Rawley, Francisco Ruiz-Aliseda, Metin Sengul and Peter Zemsky as well as participants to the 2011 CRES conference, the 2012 Atlanta Competitive Advantage Conference, the 2012 Strategy Research Forum, the 2012 Duke Strategy Conference, and the Wharton Management Department Brownbag Seminar for comments on previous versions of this paper. 


\section{INTRODUCTION}

Strategy scholars have studied strategic factor markets to understand when resource buyers could make an economic profit (Barney, 1986). In particular, scholars have made great strides studying the role of differences in information about returns (Makadok, 2001; Makadok and Barney, 2001; Denrell, Fang and Winter, 2003; Maritan and Florence, 2008; Ross, 2012) and of buyer-resources synergies (Barney, 1988; Adegbesan, 2009).

Extant formal research has made two implicit assumptions. First, those works assume that resource sellers are taking no action besides showing up to the market. We know little about what sellers do to improve their position before the factor market opens and the implications of these actions. In this paper, I will focus on one important type of action that sellers can take: the development of resources before their sale in the factor market. Prior research has taken the quality of resources sold in the factor market as given. I relax that assumption in this paper by studying resource development by firms active on the supply side of the factor market.

The second implicit assumption is that buyers of resources are not competitors in the product market. With the exception of Asmussen (2010), extant works model factor markets as if buyers of resource were using resources to collect an abstract stream of revenues rather than actually deploying the resource in a competitive product market where competitors are also buyers of resources. This matters because competitive conditions in the product market ultimately determine the returns to the deployment of resources (Grahovac and Miller, 2009; Asmussen, 2010; Costa, Cool and Dierickx, 2012). Moreover, if buyers are also competitors in the product markets they may attempt to preempt resources to deny them to their competitor. All this directly bears on how much a buyer will want to pay for a resource (and resource quality). Yet we know very little about how resource-based competition in product markets shapes factor markets. In this paper, I will explicitly derive the value of resources in the factor market in relationship to their effect on profits in the product market.

I use a formal model where sellers of resources develop resources before selling them in the factor market and where buyers deploy the resources to compete in a product market. With this model, I can explore how competition between resource buyers in the product market drives resource 
development by resource sellers.

My results offer several insights into the role of competition in factor markets at both the seller level and buyer level. First, I find that resource prices in the factor market depend on both their use value and their preemption value, i.e., the value of denying a competitor access to a resource in the product market. Because of this, returns to resource development are higher in an industry where resources are sold before they are developed compared to an industry where resource development is integrated with resource deployment. Resource sellers adjust their development efforts to both the use and the preemption value of the resource they sale. By contrast, in an industry where development is integrated, firms only care about the use value of the resource they develop because their own resource development effort does not deprive their competitor from the opportunity to develop a resource.

Second, I find that resource combination, whether additive (resource qualities add up) or exclusive (only the quality of the better resources matter), determines the type of development equilibrium. If combination is additive, sellers develop resources at similar levels. However, if combination is exclusive (only the best resource matters), I find that one seller develops at a high level whereas the other develops at a low level. Thus resources become heterogeneous even though there are no initial differences among firms. This contributes to the stream of papers explaining resource development heterogeneity as the result of strategic interactions (Ruiz-Aliseda and Zemsky, 2006; Chatain and Zemsky, 2011), thus exploring how "firm heterogeneity is an endogenous creation of economic actors" (Mahoney and Pandian, 1992: 374) in an equilibrium setting.

Finally, in analyzing how the intensity of rivalry in the product market influences resource sellers' development decisions, I find that greater rivalry increases the preemption value of the resources and increases further the wedge between investment incentives in industries with strategic factor markets compared to industries where development is integrated with deployment. Because of this, greater rivalry in the product market causes specialized resource sellers to develop resources above and beyond what integrated firms would themselves do.

The paper proceeds as follows. The following section discusses the main features of strategic 
factor markets and related literatures. I follow with the description of the model. I then examine equilibrium resource development in two scenarios: development before sale, and sale (exclusive contracting) before development. Finally, I focus on the impact of rivalry in the product market on resource development. All proofs are in an appendix.

\section{STRATEGIC FACTOR MARKETS AND INTERNAL RESOURCE DEVELOPMENT Resource development possibilities at the firm and industry levels}

Strategic factor markets are where "firms buy and sell the resources necessary to implement their strategies (Hirshleifer, 1980)" (Barney, 1986: 1232). A leading reason why firms might buy resources in factor markets is that they can find in these markets the resources that they need to compete but that they cannot develop internally (Capron and Mitchell, 2009). The external acquisition of capabilities is thus an important aspect of a resource-based strategy for firms that find themselves constrained in terms of development.

Penrose's (1959) analysis of the growth of firms offers two reasons why firms may find the development of new resources and capabilities difficult (Kor and Mahoney, 2000). First, resource development, and innovation, depend on idiosyncratic knowledge that is distributed heterogeneously across firms (Penrose, 1959:25), and difficult to transmit across firm boundaries (Kogut and Zander, 1992). As a consequence, each firm within an industry will have access to only a subset of the

resource development opportunities that the industry as a whole can exploit. Second, firms may be constrained by a limited amount of slack managerial services or experience needed to guide the process of resource development (Kor and Mahoney, 2005). Without enough of these services they cannot develop new resources and capabilities.

The constraints placed on the internal development of resources are an essential motivation for the external acquisition of resources, especially those of technological nature (e.g., Chaudhuri and Tabrizi, 1999; Graebner, 2004; Ranft and Lord, 2002). As argued in those works, firms such as Cisco, Intel and Microsoft use strategic factor markets to procure the resources and knowledge they cannot generate themselves. For similar reasons, Google, Facebook and Yahoo have also been re- 
cently regular acquirers of external resources. ${ }^{1}$ Overall, this stream of research suggests that the external acquisition of resources is an essential tool to renew and expand a resource base that constraints future development (Capron and Mitchell, 2009).

The external acquisition of resource allows breaking from the limitations of internal development by allowing the procurement of more resources than can be developed internally. Moreover, absent antitrust restrictions, firms can acquire multiple resources, as long as they are willing to offer the highest price to the seller. ${ }^{2}$ Accordingly, the model does not restrict resource buyers' ability to bid (and possibly win) for the resources available on the market as long as the bids are rational given the actions of competitors.

External acquisition is possible if there are indeed other resources to be acquired. Multiple resource development opportunities will exist within an industry if, for instance, the underlying technologies used allow for various product and process innovation. This will be the case in R\&D intensive industries, as well as industries where customers have heterogeneous tastes allowing for the development of differentiated brands.

In these industries the supply side of strategic factor markets can be very active. For instance venture capitalists who back technological startups often do not intend to remain shareholders for the long run. Their preferred exit strategy is to sell the firm and its resources to a strategic buyer.

Summing up, it is assumed throughout the paper that firms cannot develop more than one new resource or capability at a time due to constraints on the capacity of managerial services or to limited access to relevant knowledge. However, it will be assumed that there are two such opportunities available in the industry considered as a whole and that strategic factor markets allow firms to break from internal resource development constraints. Table 1 summarizes these arguments and provides further illustrations.

\footnotetext{
${ }^{1}$ For example, Google made more than 100 acquisitions between 2001 and 2011. Yahoo made more than 60 acquisitions between 1997 and 2011. Facebook representatives announced in August 2011 a plan to make 20 acquisitions in 2011. Source: http://www.bloomberg.com/news/2011-08-23/facebook-steps-up-acquisitions-to-add-users-as-googlerivalry-grows-tech.html. Retrieved October 22, 2012.

${ }^{2} \mathrm{~A}$ similar assumption is made in models of strategic interactions in input markets where one bidder can potentially buy the entire supply of inputs (Stalh, 1988)
} 
Table 1: Summary and illustration of assumptions on resource development at levels of firms and industry

\begin{tabular}{|c|c|c|}
\hline Assumption & Mechanisms & Illustrations \\
\hline $\begin{array}{l}\text { Multiple resources can be } \\
\text { developed within the industry } \\
\text { - Formal assumption: two } \\
\text { resources are developed in } \\
\text { the industry }\end{array}$ & $\begin{array}{l}\text { Multiple paths available to develop } \\
\text { resources able to improve products } \\
\text { and processes }\end{array}$ & $\begin{array}{l}\text { Industries with continuous product } \\
\text { innovation (e.g., biotech, IT, } \\
\text { mobile computing); Industries with } \\
\text { a variety of consumer preferences } \\
\text { (e.g., consumer goods); Industries } \\
\text { where process innovations of } \\
\text { different nature are possible (e.g., } \\
\text { integrated vs. minimills in } \\
\text { steelmaking) }\end{array}$ \\
\hline \multirow[t]{2}{*}{$\begin{array}{l}\text { A given firm can develop fewer } \\
\text { resources than the industry as a } \\
\text { whole } \\
\text { - Formal assumption: a firm } \\
\text { (specialized resource } \\
\text { developer or firm integrating } \\
\text { resource development with } \\
\text { deployment) cannot develop } \\
\text { more than one resource at a } \\
\text { time }\end{array}$} & $\begin{array}{l}\text { Impactedness of relevant } \\
\text { knowledge due to path dependence } \\
\text { of firm-specific managerial services } \\
\text { restricts and orients development } \\
\text { possibilities (Penrose, 1959) }\end{array}$ & $\begin{array}{l}\text { A traditional camera company } \\
\text { specialized in high quality optics } \\
\text { will find development of own } \\
\text { electronics sensors impossible, } \\
\text { while a consumer electronics firm } \\
\text { selling camera will find own } \\
\text { development of high quality optics } \\
\text { impossible, yet both types of } \\
\text { innovations are relevant for the } \\
\text { industry (e.g., Leica vs. Panasonic) }\end{array}$ \\
\hline & $\begin{array}{l}\text { Lack of slack in managerial } \\
\text { services precludes development of } \\
\text { multiple resources (Kor and } \\
\text { Mahoney, 2005; Penrose, 1959) }\end{array}$ & $\begin{array}{l}\text { A firm with brand development } \\
\text { capabilities cannot develop } \\
\text { multiple new brands at the same } \\
\text { time due to lack of managerial } \\
\text { slack (e.g., Tod's S.p.A. sequential } \\
\text { acquisition and development of } \\
\text { luxury shoe brands) }\end{array}$ \\
\hline \multirow{2}{*}{$\begin{array}{l}\text { A firm can relax internal } \\
\text { constraints on resource } \\
\text { development by buying resources } \\
\text { already developed on a strategic } \\
\text { factor market (or contract in such } \\
\text { market to access new resource } \\
\text { development capabilities) } \\
\text { - Formal assumption: A firm } \\
\text { can attempt to buy multiple } \\
\text { resources (no restriction on } \\
\text { bidding) }\end{array}$} & $\begin{array}{l}\text { Firms seek to acquire in strategic } \\
\text { factor markets the resources they } \\
\text { need to compete but cannot } \\
\text { develop on their own (Chaudhuri } \\
\text { and Tabrizi, 1999; Graebner, 2004; } \\
\text { Ranft and Lord, 2002) }\end{array}$ & $\begin{array}{l}\text { Pharmaceutical firms (e.g., } \\
\text { AstaZeneca, Merck, Pfizer, Roche) } \\
\text { acquiring multiple smaller, } \\
\text { VC-backed, biotechnology firms to } \\
\text { fill gaps in their product offering } \\
\text { and to compensate for } \\
\text { disappointing internal }\end{array}$ \\
\hline & $\begin{array}{l}\text { Sellers of resources seek the } \\
\text { highest price for their resources. } \\
\text { No external limitations (e.g., } \\
\text { antitrust) to the acquisition of } \\
\text { multiple resources (e.g., resource } \\
\text { acquisition does foreclose } \\
\text { competitors from the product } \\
\text { market) }\end{array}$ & $\begin{array}{l}\text { Technological acquisitions in } \\
\text { technology markets (e.g., Cisco, } \\
\text { Intel, Google, Microsoft, Apple, } \\
\text { Facebook) to expand competence } \\
\text { base and product portfolio into new } \\
\text { areas that cannot be reached } \\
\text { through internal development } 6\end{array}$ \\
\hline
\end{tabular}




\section{Constraints on resource combination and integration}

While resource acquisition is a matter of bidding higher than the competition, resource integration, and thus combination, requires the use of internal managerial services to attend to the integration process (Penrose, 1959). This process is far from simple, as made clear by the technology acquisition integration literature (e.g., Ranft and Lord, 2002; Puranam, Singh and Chaudhuri, 2009).

I will explore two polar cases for the combination of resources: additive combination and exclusive combination. In the additive case, the combination of two resources of respective qualities $R_{1}$ and $R_{2}$ is equivalent to a resource of quality $R_{1}+R_{2}$. In the exclusive case, the combination of two resources of qualities $R_{1}$ and $R_{2}$ creates a resource whose quality is the maximum of $R_{1}$ and $R_{2}$. The additive case is intuitive: it describes the case when using one resource does not affect the other. The exclusive case requires more elaboration.

A good source of insights for resource combination is the literature on post-merger integration. A merger between two firms is the logical equivalent of combining two sets of resources to create a new one and the M\&A market is a leading example of a factor market (Barney 1986, 1988). Therefore, what happens when two firms merge can give us insights on the outcome of the combination of two resources.

This literature emphasizes that integrating relatively similar factors of production can be difficult. Case studies of actual attempts to combine capabilities have shown that it was sometimes preferable to pick the better of two available capabilities and abandon the other. For instance, managers of the combined HP and Compaq entity adopted the policy of picking the best resource or capability available in either firm without attempting to combine them (Burgelman and Meza, 2004). Similarly, Cassiman, Columbo, Gerrone and Veugelers (2005) find that firms combining comparable R\&D resources were likely to decide on cuts and shut downs (as in the case of R\&D capabilities ) if resources proved redundant. These examples suggest that sometimes the best way to combine two resources is to simply use the better one and abandon the other.

Firms will use exclusively the better resource if the marginal contribution of the lower quality resource is zero. This may happen when the resources that are deployed are indivisible and "scale- 
free", in the sense that their opportunity cost of deployment is zero (Levinthal and $\mathrm{Wu}, 2010)$. If both resources are going to supply the same service to the firm, but the best resource can be deployed wherever the worse resource needs to be deployed, then the best policy is to deploy only the better resource. Similarly, when the marginal contribution of a lower quality resource is positive, but is still less than the recurring cost of maintaining the resource, it is best to only use the better resource.

Finally, the exclusive case can be seen as the outcome of limited integration capabilities in the buying firms. The limited availability of managerial services that restricts resource development can also, to a lesser extent, hinder resource integration, leading a firm to concentrate on the better of two resources at hand.

Table 2 presents examples and rationales for the exclusive case. For instance, Procter \& Gamble decided to terminate a brand of toilet paper it owned (White Cloud) and to only keep the Charmin brand. Presumably, the White Cloud brand was still valuable, but the incremental cost of maintaining and managing it was less than the incremental benefit it could provide. Accordingly, I will contrast development strategies in the exclusive combination case with those in the additive case.

\section{Rivalry in the product market and the demand for strategic factors}

This paper incorporates product markets in the analysis of factor markets and focuses on the role of competition, understood as level of rivalry, between resource buyers. This builds on the idea that resource buyers are willing to pay for resources in function of the value these resources allow capturing in the product market (Priem and Butler, 2001; Peteraf and Barney, 2003).

Analyzing product market competition is most relevant when resource buyers are in an intermediary situation between being a monopolist in its product markets and a small participant in a perfectly competitive market. If the buyer is a monopolist in its own market, the benefit it can accrue from deploying a resource does not depend on competition there, as there is no competition to start with. The same is true if the resource buyer is active in a perfectly competitive product market. Because all firms have a negligible impact on the market price, any acquisition of resource will have a negligible effect on other firms.

Accordingly, I focus on a product market where the number of firms is small. For analytical 
Table 2: Exclusive outcomes in resource combination (Value of combined resource is $\max \left(R_{1}, R_{2}\right)$ )

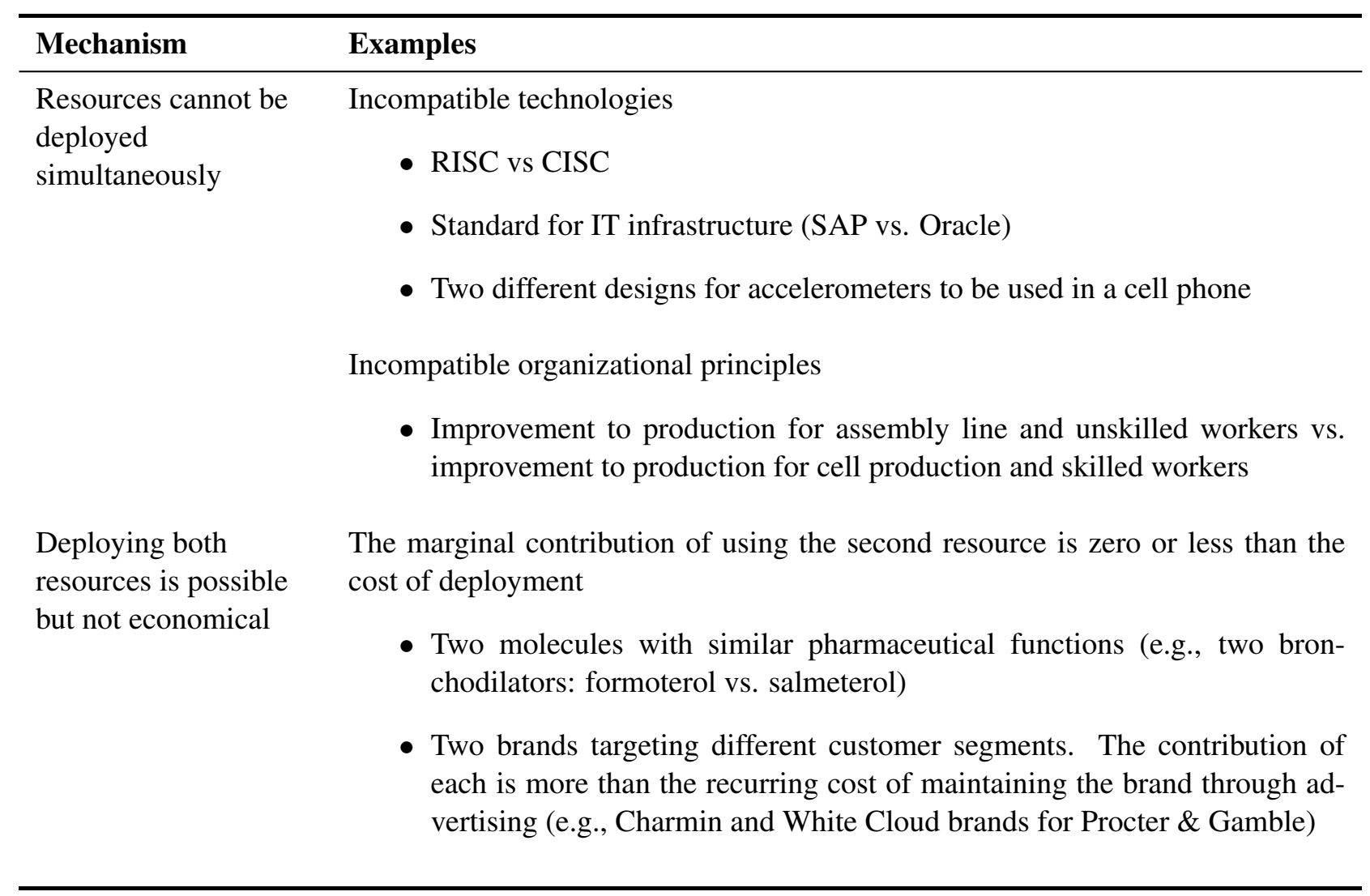

tractability, I assume two potential buyers who are competing against each other in a product market. Moreover, I will seek to make the analyses robust across a wide range of models of product market competition by relying on assumptions shared by many of these models.

\section{Related literatures}

Other streams of research have explicitly studied the relationship between competition in the product market and outcomes in various markets for inputs. What answers can they provide to strategy scholars interested in factor markets, investment in resources, and product market competition?

The market intermediation literature (e.g., Stahl, 1988) focuses on whether prices deviate from a standard supply and demand outcome, but has little to say on the investment incentives of input producers. In these models, firms act as intermediaries between producers and consumers, and want to bid up the supply to become a monopolist. This typically results in high prices on both the input and the product market but zero profits for the intermediaries. While the tendency to preempt the 
input is also at play in my model, the goal of preemption is not in itself to limit quantities in the product market but rather to reduce the relative efficiency of a competitor.

In the production outsourcing literature (e.g., Gupta and Loulou, 1998; Cachon and Harker, 2004; Gilbert, Xia and Yu, 2006), firms competing in the product market face excessive incentives to reduce their costs, leading to deleterious competition. They can improve their lot by outsourcing production and cost reduction to an upstream supplier. In these papers, firms buy components of the final product, and returns from investments are proportional to the quantity sold. Double marginalization will keep prices high, reduce the quantity sold, and reduce the investment incentives of the supplier, which makes the buying firms better off. This mechanism is markedly different from what I study in this paper. In this paper sellers build indivisible resources, such as a technology or any another knowledge asset that improves the profit functions of the resource buyers. All that matters is resource quality. As a result, double marginalization does not play a role because resources are traded as a whole prior to product market competition.

The relationship between product and strategic factor markets relates closely to contributions made by the literature on markets for innovation. This literature typically asks whether innovators are better off licensing an innovation to incumbents or entering the product market to exploit it themselves (Arora and Fosfuri, 2003). It has, for instance, found that if markets for innovation are not functioning well, innovators will more often enter the product market, strengthening competition there (Gans and Stern, 2000). Authors have also argued that competition in the product market could be leveraged by sellers of innovation to protect them from opportunistic behavior by buyers (Anton and Yao, 1994), alleviating informational frictions in the market for innovation. However, the works that have explored differential incentives for investment among actors have usually contrasted entrants and incumbents in the product market (Arrow, 1962) rather than directly comparing sellers and users of strategic factors. This sheds less light on how preexisting conditions in the product market among resource buyers affect resource sellers' incentives to develop better resources.

Finally, the literatures on vertical foreclosure (Rey and Tirole, 2007; Gabszewicz and Zanaj, 2008) and on raising rivals' costs (Salop and Scheffman, 1983) focuses on how preemptive actions 
in a market for an intermediary good can affect competition in the product market. However, research in these streams typically does not endogenize the investment incentives of the sellers of intermediary goods. In contrast, the model presented in this paper includes actions by sellers of intermediary goods (here, strategic resources) and studies in details their investment incentives.

\section{MODEL SETUP AND FORMAL ASSUMPTIONS}

The model is deliberately developed to be relevant under a wide range of classic models of product market competition. This approach helps to broaden the domain of validity of the model and eliminates the need for ancillary assumptions that may make analysis more cumbersome and less transparent.

The model comprises two resource buyers denoted by $B_{i}, i \in\{1,2\}$ that compete in a product market and two resource sellers denoted by $S_{i}, i \in\{1,2\}$. Resource sellers each develop and sell one resource to resource buyers. Table 3 brings together the main symbols and notations used in the paper and shows when they are used.

\section{Resource development technology}

Resource sellers have access to a technology that enables them to develop one resource at a cost that increases with the quality of the resource. Let $C(x)$ be the cost of developing a resource of quality $x$. Assume the function $C(x)$ is twice continuously differentiable such that:

$$
C(0)=0, \quad \frac{\partial C(x)}{\partial x}>0, \quad \frac{\partial^{2} C(x)}{\partial x^{2}}>0, x \geq 0 .
$$

With this technology, seller $S_{i}$ develops a resource to quality level $R_{i}$ for a cost $C\left(R_{i}\right)$ and sells it on the factor market.

\section{Assumptions on resource integration}

Because factor market competition may result in a buyer buying the two resources that are put to sale, we need to specify how resources combine. Following our discussion of the outcomes of resource 
Table 3: Notation

\section{Construct}

Symbol

\section{Baseline elements}

Cost of developing resource to quality level $x$

$$
\begin{gathered}
C(x) \\
g(x, y) \\
\Pi_{i}^{B}(x, y) \\
R_{i} \\
b_{j}^{i} \\
p_{i}\left(R_{i}, R_{-i}\right) \\
\Pi_{i}^{S} \\
\left.\bar{\Pi}_{i}^{B}\left(R_{i}, R_{-i}\right)\right)
\end{gathered}
$$

Combined quality of resources of individual quality $x$ and $y$

Buyer $B_{i}$ 's product market profits, for resource quality $x$ and competitor's resource quality $y: \quad \Pi_{i}^{B}(x, y)$

Resource development level (quality) decided by seller $S_{i}$

Bid offered by buyer $B_{i}$ for resource sold by seller $S_{j}$

Seller's $S_{i}$ revenues given $R_{i}$ and $R_{-i}$

Seller's $S_{i}$ profit

Integrated firm $B_{i}$ 's profit net of resource development cost

\section{Equilibrium values of resource development level}

Development when resources are monopolized by one buyer

Symmetric development by sellers with additive resources

$R^{\text {Additive }}$

Asymmetric development by sellers with exclusive resources $R^{H}, R^{L}$

Symmetric development by firms integrating development and deployment

$R^{I D}$

Development when resources are not monopolized by one buyer

Symmetric development by sellers with additive resources $R^{A d d *}$

Asymmetric development by sellers with exclusive resources $R^{H *}, R^{L *}$

Development when development is contracted upon ex ante

Symmetric development by sellers with additive resources

$R^{A d d * *}$

Asymmetric development by sellers with exclusive resources

$$
R^{H * *}, R^{L * *}
$$

\section{Effect of changes in rivalry in the product market on equilibrium development}

Parameter shifting the level of rivalry in the product market 
combination, I make the following formal assumptions. Combining two resources of respective qualities $x$ and $y$ provides a benefit $g(x, y)$.

$$
g(x, y)=\left\{\begin{array}{l}
x+y \text { when resource combination is additive } \\
\max (x, y) \text { when resource combination is exclusive }
\end{array}\right.
$$

\section{Assumptions on product market competition}

Once resources are transferred to the buyers and integrated, product market competition unfolds. The buyers' profits depend on the level of development of resources (i.e., the quality level of resources) and their allocation across buyers. The following notation uses generalized functions to represent profits in the product market and to account for the quality of resources and their allocation across competitors. The profit of a resource buyer before any payment to a resource seller is written $\Pi_{i}^{B}(x, y)$ where the first variable of the function $(x)$ is the quality of the resource (or the combination of resources) owned by buyer $B_{i}$ and the second variable $(y)$ is the quality of the resource or combination of resources owned by its rival $B_{-i}$. I will assume that these functions are identical across buyers and I will drop the buyer index accordingly.

I assume that the function $\Pi^{B}$ is twice continuously differentiable in its arguments. Moreover, I assume:

$$
\frac{\partial \Pi^{B}(x, y)}{\partial x}>0, \quad \frac{\partial \Pi^{B}(x, y)}{\partial y}<0, \quad \frac{\partial^{2} \Pi^{B}(x, y)}{\partial x \partial y} \leq 0 .
$$

The first assumption means that a firm's profit increases when it deploys a resource of higher quality. The second means that a firm's profits decrease when a competitor uses better resources. The third assumption means that the effect of a firm's resource decreases when the competitor's resource improves (i.e., resource qualities are strategic substitutes). Furthermore, I assume that $\Pi^{B}(x, y)$ is weakly convex in its second argument. This is consistent with the idea that as a competitor becomes better, a focal firm's profitability is less and less affected because it is reaching a floor.

These assumptions cover many workhorse models of competition in the product market. In particular, the assumption that resource levels are strategic substitutes is verified when resources reduce 
cost or improve quality in many classic models of oligopolistic competition (Amir and Wooders, 2000; Athey and Schmutzler, 2001). These include Cournot and differentiated Bertrand with linear demand and linear costs, horizontal competition with quadratic costs and two firms. On the basis of these assumptions the analyses below will be valid across a wide spectrum of models.

Resource quality levels, however, can also be strategic complements in some important situations. Think for instance of resources that increase the size of the market by drawing new customers rather than by stealing customers from the competitor, or when investing in a resource is a make-orbreak effort to avoid bankruptcy. The framework of this paper could be adapted in a straightforward manner to accommodate these cases.

\section{Resource development by sellers to the factor market and integrated development benchmark}

The main model will analyze resource development strategies when resources are developed independently by sellers prior to the sale. This portrays well the market for the ownership of startups, when owners of startups have already developed capabilities and resources and are acquired by larger companies that will integrate them in their operations.

The left panel of Figure 1 depicts the base model while an important benchmark model is depicted on the right panel. In the base model of development for strategic factor market resources are developed by sellers that are separate from the buyers. There is rivalry in development (developers face a competitor) and in deployment of resources (both buyers are competing in a product market). Resources are allocated to firms competing in the product market thanks to the operation of a factor market.

In the benchmark model we make the thought experiment of removing the strategic factor market while keeping every other initial condition similar. Resource development is now integrated with resource deployment and product market activities. Similarly to the base model, there is rivalry for development and for the deployment of resources. The number of resources to be developed in the industry is also the same. The comparison of the outcomes of the benchmark model to the base model answers the following question: "How does the existence of a strategic factor market in an industry affects resource development patterns under rivalry compared to an industry where there is 

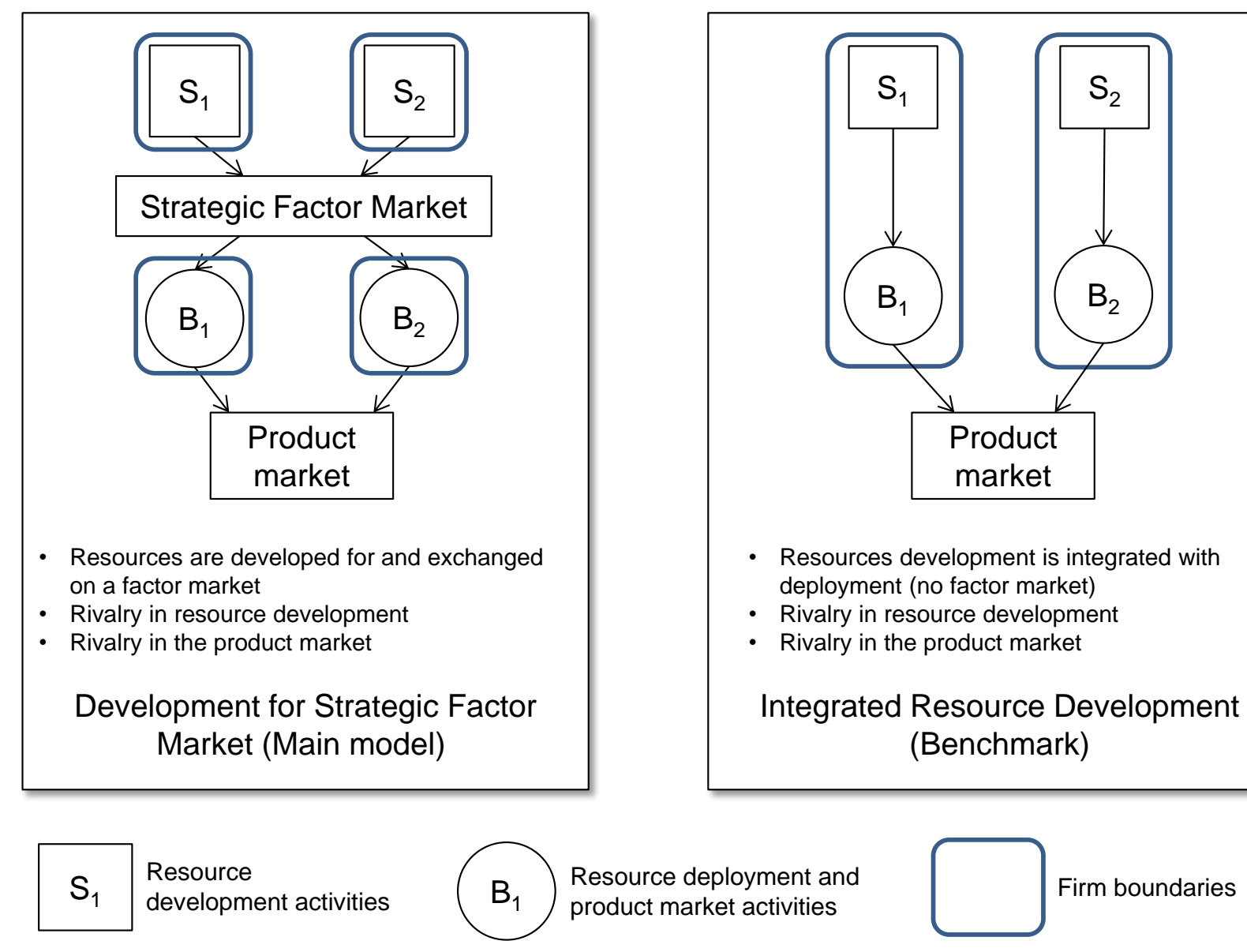

- Resources development is integrated with deployment (no factor market)

- Rivalry in resource development

- Rivalry in the product market

\section{Integrated Resource Development} (Benchmark)

Figure 1: Overview of the main model and of the integrated resource development benchmark

no strategic factor market?" Any difference in outcome between the base model and the benchmark can be attributed to the difference in initial conditions.

Sellers develop resources independently and non-cooperatively before selling them in auctions that are held simultaneously. Previous work has used auctions to model factor markets (Makadok, 2001; Maritan and Florence, 2008), which describes well markets where sellers set out to generate competition among buyers, as is often the case in factor markets. ${ }^{3}$

The time line of the game is as follows:

1. Resource development: Sellers invest to develop a resource at a certain quality level giving

\footnotetext{
${ }^{3}$ An alternative is to use a cooperative game approach (e.g., Lippman and Rumelt, 2003; Adegbesan, 2009) embedded in a biform approach (Brandenburger and Stuart, 2007). The drawback of such approach is that the core of the cooperative game may fail to exist when buyers interact after resources are allocated (Jehiel and Moldovanu, 1996).
} 
resources $R_{1}$ and $R_{2}$.

2. Factor market competition: Sellers set simultaneous second price auctions to sell their resources. Sellers transfer the ownership of the resource to the highest bidder and collect revenues.

3. (If necessary.) Resource integration: If a buyer bought resources $R_{1}$ and $R_{2}$, it combines them into a new resource of quality $g\left(R_{1}, R_{2}\right)$.

4. Product market competition: Buyers compete with each other in the product market. Their profits are affected by the quality of the resources they own and by the quality of the resources their competitor owns.

In the model all players are forward looking and anticipate what will happen in the next stages of the game. Resource buyers bid in the auction anticipating what will happen in the product market. Resource sellers make investment decisions anticipating the equilibrium bids in the factor market. I solve the model by backward induction. I first solve the model in the factor market (stage 2 above) before turning to the optimal resource development (stage 1). Note that the outcome of product market competition given resource allocation and quality levels (stages 3 and 4) is already summarized by the profit function $\Pi^{B}$.

\section{FACTOR MARKET COMPETITION (STAGE 2)}

\section{Assumptions on the factor market}

The factor market consists of two simultaneous second-price sealed-bid auctions. Neither sellers nor buyers coordinate their actions. Buyers simultaneously submit bids to each seller. Each seller sells the resource to the highest bidder for the resource it controls, and does not coordinate with the other bidder. If the bids for the same resource are identical, the seller randomly picks a winner, with each buyer winning with strictly positive probability.

Resources are not sold as a bundle, reflecting the assumption that sellers are not cooperating, even though buyers may want to combine resources. This protocol is rather conservative with respect 
to seller revenues. In an auction, by definition, sellers cannot name their price, which creates a ceiling on how much value they will be able to extract. Moreover, the auctions are simultaneous, which means that buyers can play each seller against the other. ${ }^{4}$

Buyers will submit bids for a resource given their expectations about who will acquire the other resources. As these are second price auctions, a buyer's dominant strategy is to submit a bid equal to the maximum amount it is willing to pay for the resource. In order to determine bids, we have to keep in mind that a firm's optimal bid for a resource is the difference between its profits in the product market if it owns the resource and those profits if its competitor owns the resource instead (Jehiel and Moldovanu, 1996).

Bids will form an equilibrium when the final ownership of resources given the bids is consistent with the expectations under which the bids were formed. The method to characterize equilibria is to assume a particular allocation of resources after the auction (e.g., one buyer gets both resources, or each buyer gets one resource), find the optimal bids given the anticipated allocation, and then check if the optimal bids indeed lead to the assumed outcome.

\section{Numerical example}

To make these ideas concrete, we start with a numerical example. Assume the following product market profits given the ownership of resources:

Profit with $R_{1}$ and $\left.R_{2}=\Pi^{B}\left(g\left(R_{1}, R_{2}\right), 0\right)\right)=11, \quad$ Profit with only $R_{2}=\Pi^{B}\left(R_{2}, R_{1}\right)=3$,

Profit with only $R_{1}=\Pi^{B}\left(R_{1}, R_{2}\right)=4, \quad$ Profit with no resources $=\Pi^{B}\left(0, g\left(R_{1}, R_{2}\right)\right)=1$.

\footnotetext{
${ }^{4}$ The simultaneity of the auctions reflects the idea that both sellers have similar incentives to be first to sell their resource and that a contest to be first would result in a draw. An alternative would be to have resources sold sequentially, with one seller selling its resource first. Appendix B explores such a model where the order of sale is randomly determined. I thank an anonymous referee for suggesting to explore this alternative.
} 
The incremental value of owning a second resource while controlling the other is more than that of owning one resource versus none. For example:

$$
\begin{aligned}
& \left.\Pi^{B}\left(g\left(R_{1}, R_{2}\right), 0\right)\right)-\Pi^{B}\left(R_{1}, R_{2}\right)=11-4=7, \\
& \Pi^{B}\left(R_{2}, R_{1}\right)-\Pi^{B}\left(0, g\left(R_{1}, R_{2}\right)\right)=3-1=2 .
\end{aligned}
$$

To determine equilibrium prices, we need to make an assumption regarding the eventual allocation of the resources, determine the prices that follow from the assumption, and check that these prices verify the assumption.

We will see below that valuations like these imply that one buyer will acquire both resources at equilibrium. Assume thus that one buyer ( $B_{1}$, without loss of generality) anticipates winning the resources in both auctions. In a second price auction buyers bid the maximum price they are willing to pay for a resource, as this is a dominant strategy. Buyer $B_{1}$ 's bids will be the following:

$$
\begin{aligned}
& B_{1} \text { 's Bid for } R_{1}=\text { Profit with } R_{1} \text { and } R_{2}-\text { Profit with only } R_{2}=11-3=8 \\
& B_{1} \text { 's Bid for } R_{2}=\text { Profit with } R_{1} \text { and } R_{2} \text { - Profit with only } R_{1}=11-4=7 \text {. }
\end{aligned}
$$

Notice that the sum of the bids is more than the value of owning both resources. This is because each bid is equal to buyer $B_{1}$ 's willingness to pay for a resource conditional on its winning the other resource.

In an equilibrium, buyer $B_{2}$ correctly anticipates it will not win either resource. Its bids are equals to its willingness to pay for each resource conditional on not winning the other resource.

$B_{2}$ 's Bid for $R_{1}=$ Profit with only $R_{1}-$ Profit with no resource $=4-1=3$, $B_{2}$ 's Bid for $R_{2}=$ Profit with only $R_{2}$ - Profit with no resource $=3-1=2$.

We see that buyer $B_{1}$ always bids higher than buyer $B_{2}$. Accordingly, it receives the two resources, which is what we assumed initially. As a result, these four bids form an equilibrium. This 
can be confirmed by looking at potential deviations by each player, holding the other player's bids constant, and checking that the deviations do not allow for strictly superior profits.

Neither buyer $B_{1}$ nor buyer $B_{2}$ can make strictly more money by bidding less. In the case of buyer $B_{1}$, it could actually lose the resources by bidding too low, while buyer $B_{2}$ is indifferent, knowing it will not win anyway.

Buyer $B_{1}$ cannot make strictly more money by bidding more, as any bid would exceed its willingness-to-pay in the most favorable scenario. Is it possible, however, that buyer $B_{2}$ submits higher bids? The answer is no. Doing so would be irrational given it anticipates not winning both resources. Its bid would exceed whatever additional profits it can expect to earn thanks to the resource.

Moreover, in an equilibrium, both buyers cannot bid as if they both anticipated getting the two resources. To see this, suppose that both buyers anticipate winning both resources. In that case, given their beliefs, they would both bid 8 for resource $R_{1}$ and 7 for resource $R_{2}$, leading to a tie. But in a tie, the winner is randomly and independently determined. With these bids, a buyer is losing money in expectation because there is a strictly positive probability that it wins both resources, paying $8+$ $7=13$ for resources that are worth only 11 , netting a profit of -2 . A buyer would also overpay if it obtained only one resource, as its bid was made anticipating that it would get both resources. For instance, it would pay 8 for resource $R_{1}$ while the value of owning it is only 2 when resource $R_{2}$ is not owned at the same time.

Because of this, if both buyers bid high, each buyer is better off deviating and bidding less in order to lose the auction for both resources, ensuring it gets 1, the profit without any resources. But then, if a buyer anticipates losing, its optimal bids for $R_{1}$ and $R_{2}$ are respectively 3 and 2 , so this buyer's bids (and the final prices in the auctions) go back to the equilibrium described above.

The auction concludes with the highest bid for resource $R_{1}$ at 8 , and the second highest at 2 . Thus the seller of resource $R_{1}$ receives 2 . Similarly, the highest bid for resource $R_{2}$ is 7 , and the second-highest bid is 3 . The seller of resource $R_{2}$ receives 3 .

Modeling the auctions as first price auction with a smallest monetary increment (e.g., one cent) 
would generate similar revenues, plus or minus a unit of monetary increment. ${ }^{5}$

\section{Formal characterization of the equilibrium in the factor market}

To understand investment incentives by sellers, we need to determine the prices at which the resources will be sold in the factor market. These prices depend on buyer's valuations, which in turn depend on the eventual allocation of resources across buyers. Thus, we will need to formally determine the conditions under which resources are bought by the same buyer or by different buyers. To do so, the procedure is to assume a specific outcome to the factor market and derive the conditions under which it is actually an equilibrium.

We analyze first the outcome in which one buyer gets both resources. As seen above, if both resources 1 and 2 are expected to be acquired by buyer $B_{1}$ at equilibrium, then buyer $B_{2}$ 's bid for resource 1 will reflect that it does not expect to get resource $R_{2}$ and its bid for resource $R_{2}$ will reflect that it does not expect to get resource $R_{1}$. Conversely, buyer $B_{1}$ 's bids for each resource will reflect the expectation that it will also acquire the other.

In the case of resources of respective qualities $R_{1}$ and $R_{2}$ we would see the following bids in the anticipation that buyer $B_{1}$ will ultimately acquire both resources. Let $b_{j}^{i}$ be the bid that buyer $B_{i}$ submits for resource $R_{j}$. Starting with buyer $B_{1}$ 's bids, we have:

$$
b_{1}^{1}=\Pi^{B}\left(g\left(R_{1}, R_{2}\right), 0\right)-\Pi^{B}\left(R_{2}, R_{1}\right), \quad b_{2}^{1}=\Pi^{B}\left(g\left(R_{1}, R_{2}\right), 0\right)-\Pi^{B}\left(R_{1}, R_{2}\right) .
$$

The bid for resource $1\left(b_{1}^{1}\right)$ is the difference between buyer $B_{1}$ 's product market profits if it owned the resource $\left(\Pi^{B}\left(g\left(R_{1}, R_{2}\right), 0\right)\right)$ and if it did not, assuming it is left with resource $R_{2}$ only, $\Pi^{B}\left(R_{2}, R_{1}\right)$. The bids can be decomposed in two parts: the use value for the resource, which reflects the increase in profits if the resource is deployed by the buyer, and the preemptive value for the resource, which reflects the value of preventing the competing buyers from deploying the resource. Formally, denoting $\Pi^{B}\left(R_{2}, 0\right)$ as the profits of buyer $B_{1}$ in the situation where resource

\footnotetext{
${ }^{5}$ The second price format is strategically equivalent to an ascending auction (English auction) when there are two buyers (Krishna, 2009: 133) and the smallest monetary increment would guarantee the existence of a pure strategy equilibrium in the first price auction.
} 
$R_{1}$ is not deployed, we have:

$$
b_{1}^{1}=\underbrace{\Pi^{B}\left(g\left(R_{1}, R_{2}\right), 0\right)-\Pi^{B}\left(R_{2}, 0\right)}_{\text {Use value for } R_{1}}+\underbrace{\Pi^{B}\left(R_{2}, 0\right)-\Pi^{B}\left(R_{2}, R_{1}\right)}_{\text {Preemption value for } R_{1}} .
$$

The preemption value is always strictly positive if buyers are competing with each other in the product market. The implication is that a key feature of bidding for resources in these circumstances is the potential for overbidding, in the sense that buyers are compelled to bid above their use value for the resource. This phenomenon was shown by Jehiel and Moldovanu (1996) in the context of the auction for a single unit. Under similar expectations about the outcome of the auctions, the bids by buyer $B_{2}$ are:

$$
b_{1}^{2}=\Pi^{B}\left(R_{1}, R_{2}\right)-\Pi^{B}\left(0, g\left(R_{1}, R_{2}\right)\right), \quad b_{2}^{2}=\Pi^{B}\left(R_{1}, R_{2}\right)-\Pi^{B}\left(0, g\left(R_{1}, R_{2}\right)\right) .
$$

These bids also reflect use and preemption value. The status quo situation is that resource $R_{2}$ goes to buyer $B_{1}$, implying profits of $\Pi^{B}\left(0, R_{2}\right)$ for buyer $B_{2}$. Then:

$$
b_{1}^{2}=\underbrace{\Pi^{B}\left(R_{1}, R_{2}\right)-\Pi^{B}\left(0, R_{2}\right)}_{\text {Use value for } R_{1}}+\underbrace{\Pi^{B}\left(0, R_{2}\right)-\Pi^{B}\left(0, g\left(R_{1}, R_{2}\right)\right)}_{\text {Preemption value for } R_{1}} .
$$

All the bids submitted by the buyers $\left(b_{1}^{1}, b_{2}^{1}, b_{1}^{2}, b_{2}^{2}\right)$ form an equilibrium if they lead to the expected outcome whereby buyer $B_{1}$ gets both resources. That is, if $b_{1}^{1}>b_{1}^{2}$ and $b_{2}^{1}>b_{2}^{2}$. If these conditions are not met the equilibrium cannot be one where one buyer gets both resources. Instead, the equilibrium will be one where each buyer gets one resource.

A similar derivation starting from the assumption that resources are bought by different buyers can easily be made. The above discussion is summarized and extended in the following proposition:

Proposition 1 Given resource developments $R_{1}$ and $R_{2}$ the outcome of the factor market with si- 
multaneous second price auctions is characterized by the following inequality.

$$
\Pi^{B}\left(g\left(R_{1}, R_{2}\right), 0\right)+\Pi^{B}\left(0, g\left(R_{1}, R_{2}\right)\right)>\Pi^{B}\left(R_{1}, R_{2}\right)+\Pi^{B}\left(R_{2}, R_{1}\right)
$$

If inequality (1) holds, one buyer buys the two resources at equilibrium. In this case, there are two equilibria: either buyer $B_{1}$ or buyer $B_{2}$ gets the two resources. The equilibrium price of resource $i$ is:

$$
p_{i}\left(R_{i}, R_{-i}\right)=\Pi^{B}\left(R_{i}, R_{-i}\right)-\Pi^{B}\left(0, g\left(R_{i}, R_{-i}\right)\right)
$$

If inequality (1) is reversed and holds strictly, then each buyer buys one resource. In this case, there are two equilibria: either buyer $B_{1}$ gets resource 1 and buyer $B_{2}$ gets resource 2 , or the reverse. The equilibrium price of resource $i$ is:

$$
p_{i}\left(R_{i}, R_{-i}\right)=\Pi^{B}\left(g\left(R_{i}, R_{-i}\right), 0\right)-\Pi^{B}\left(R_{-i}, R_{i}\right)
$$

If both sides of inequality (1) are equal, then all of the above equilibria exist.

The interpretation of inequality (1) is intuitive. Preemption will happen when the sum of buyer profits grows as they become more asymmetric in terms of resource endowment. This condition will typically be satisfied in some workhorse models of product market competition (e.g., Cournot and differentiated Bertrand). In these models, total industry profits are larger when firms are asymmetric. The reason for this is that the more asymmetric firms are, the closer the product market is to being a monopoly, which ensures the highest level of profits.

Another way to interpret inequality (1) is to rewrite it as:

$$
\Pi^{B}\left(g\left(R_{1}, R_{2}\right), 0\right)-\Pi^{B}\left(R_{1}, R_{2}\right)>\Pi^{B}\left(R_{2}, R_{1}\right)-\Pi^{B}\left(0, g\left(R_{1}, R_{2}\right)\right) .
$$

On the left hand side is the benefit of controlling resource $j$ if a buyer already controls resource $i$, and on the right hand side is the benefit of controlling resource $j$ if the buyer initially controls no resource. Thanks to this, we can further understand when buyers will only buy one resource. 
If resources are less than additive, the direct benefit of owning two resources is depressed. If buyers have only little competitive impact on each other, for lack of market overlap, the benefit of denying the resource to the other buyer is also reduced. The combination of these two effects may make the willingness to pay for a second resource less than what a competitor would be ready to pay for a first resource, making preemption impossible.

To see this, consider the polar case where the combination of resources is exclusive and there is no market overlap between buyers. If profits are not affected by the other buyer's resource ownership we have: $\Pi^{B}(x, y)=\Pi^{B}(x, 0)$. Assume $R_{1}=R_{2}=R$ and let $g\left(R_{1}, R_{2}\right)=\max \left(R_{1}, R_{2}\right)$. The left hand side of (1) can be rewritten $\Pi^{B}(R, 0)+\Pi^{B}(0,0)$, while the right hand side becomes $\Pi^{B}(R, 0)+\Pi^{B}(R, 0)$. But, by assumption, $\Pi^{B}(R, 0)>\Pi^{B}(0,0)$, so we have:

$$
\Pi^{B}(R, 0)+\Pi^{B}(0,0)<\Pi^{B}(R, 0)+\Pi^{B}(R, 0)
$$

and thus inequality (1) is not satisfied.

\section{Interpretation of the multiplicity of equilibria}

Resource prices are always determinate at equilibrium. However, the identity of the eventual buyer is not, as there are multiple equilibria in which buyer $B_{1}$ and buyer $B_{2}$ play symmetric roles. This multiplicity arises because buyer $B_{1}$ and buyer $B_{2}$ are identical and value resources similarly. When they compete for resources by bidding in the factor market, neither has an advantage over the other and there is no way to determine within the model itself which buyer will prevail.

It is possible that the ex post economic profits of the buyers are not equalized by competition when the factor market closes. For instance, in our numerical example, the winner of the two resources enjoys a product market profit of 11 while paying $3+2=5$ for the resources, netting a profit of 6 whereas the other buyer enjoys profits of 1 .

However, buyers' profits ex ante are identical, as which equilibrium will happen is indeterminate. ${ }^{6}$ This outcome is fully consistent with extant research in factor market theory. Absent asym-

\footnotetext{
${ }^{6}$ Even if buyers were playing mixed strategies, their expected profits would also be similar due to buyers' identical valuations of the resources.
} 
metries in valuation and information, buyers are on a similar footing and cannot expect to make superior profits ex ante (Barney, 1986; Lippman and Rumelt, 2003). Only luck — in this case under the guise of equilibrium multiplicity — will allow a buyer to make a superior profit ex post.

This situation is well understood in game theory: the factor market takes the form of a coordination game. Considerations outside of the game, such as a buyer's reputation to be an aggressive bidder, can make one equilibrium more "focal" (Schelling, 1960) and facilitate coordination. Of course, any difference in profits ex ante due to the existence of a focal point should then be attributed to a buyer's attributes that support the existence of the focal point. ${ }^{7}$

\section{INVESTMENT IN RESOURCE QUALITY (STAGE 1)}

Resource sellers anticipate the revenues they will earn in the factor market based on the prices given by Proposition 1. Knowing this, they non-cooperatively decide how much to invest in the development of resources prior to their sale in the factor market.

Assume that resources are acquired by the same buyer (this will be relaxed later). The revenue earned by seller $S_{i}$ from the sale of a resource with quality level $R_{i}$ when the competing resource has quality level $R_{-i}$ is $p_{i}\left(R_{i}, R_{-i}\right)$ as defined in Proposition 1. With development cost $C\left(R_{i}\right)$, the seller's profit function is then:

$$
\Pi_{i}^{S}\left(R_{i}\right)=p_{i}\left(R_{i}, R_{-i}\right)-C\left(R_{i}\right)=\Pi^{B}\left(R_{i}, R_{-i}\right)-\Pi^{B}\left(0, g\left(R_{i}, R_{-i}\right)\right)-C\left(R_{i}\right) .
$$

We will look for a pure strategy Nash equilibrium of the factor market development game where seller $S_{1}$ and $S_{2}$ are simultaneously developing resources and earning profits as defined in equation (3). To characterize this equilibrium, we define a benchmark that is the outcome of the integrated development game. In the integrated development game, there is no factor market but there are two players who integrate resource development and product market activities and can develop a resource at cost $C()$. The two integrated players decide simultaneously how much to develop their resource. The integrated firms then use their newly developed resource to compete in the product

\footnotetext{
${ }^{7}$ I thank an anonymous referee for pushing for the clarification of these issues.
} 
market.

In this integrated development game, a buyer is clearly at a disadvantage if it does not develop a resource as the other buyer will develop one anyway. The symmetric Nash equilibrium $\left(R^{I D}, R^{I D}\right)$ of the buyer development game always exists and the development level $R^{I D}$ will be our benchmark. The Nash equilibria of the two games can be precisely compared because the two games are formally related to each other (see, e.g., Topkis, 1998: 183). Notice that buyer $i$ 's total profit given Buyer $-i$ 's resource development decision is:

$$
\bar{\Pi}_{i}^{B}\left(R_{i}, R_{-i}\right)=\Pi^{B}\left(R_{i}, R_{-i}\right)-C\left(R_{i}\right),
$$

and that expression (4) is very similar to expression (3).

Turning to the characterization of the Nash equilibria in resource development of the factor market development game, we find:

Proposition $2 \square$ Assume that development by sellers occurs before the sales of resources and that the outcome of the factor market is one buyer acquiring both resources. Then:

(i) A pure strategy Nash equilibrium in resource development always exists.

(ii) When resource combination is additive, there is a symmetric resource development equilibrium: $R_{1}=R_{2}=R^{\text {Additive }}$. When resource combination is exclusive, resource development is in pure strategy is asymmetric. One seller develops at level $R^{H}$ and the other at level $R^{L}$, with $R^{H}>R^{L}$.

(iii) Relative development levels are as follows: $R^{H}>R^{I D}>R^{L}$ and $R^{\text {Additive }}>R^{I D}$ where $R^{I D}$ is the development level in the symmetric Nash equilibrium of the integrated development game.

Assume that the outcome of the factor market is each buyer acquiring one resource. If resource combination is additive, we have symmetric resource development $\left(R_{1}=R_{2}=R^{\text {Add* }}\right)$. If resource combination is exclusive, any PSNE is asymmetric and development levels are such that $R^{H *}>R^{L *}$. Moreover, we have $R^{H *}>R^{I D}$ and, iff $\partial^{2} \Pi^{B}(x, y) / \partial x^{2} \geq 0$, we also have $R^{A d d *}>R^{H *}>R^{I D}$. 
The first point of Proposition 2 is that an equilibrium in pure strategy always exists (this draws on work by Amir, Garcia and Knauff (2010)). Next, the proposition emphasizes the dual effects on development strategies of the value of preemption and of the combination on resources.

Consider first the case of additive resources. Because of the possibility of preemption, a seller of resources always has a greater incentive to develop the resource than a buyer would. Looking at equation (3), we see that developing a resource $R_{i}$ increases revenues in two ways: by increasing the use value $\left(\Pi^{B}\left(R_{i}, R_{-i}\right)\right)$ and by increasing the preemption value $\left(-\Pi^{B}\left(0, g\left(R_{i}, R_{-i}\right)\right)\right)$. By contrast, in the integrated development game, each buyer only considers the use value of the resource given the other buyer's development decision and does not account for the preemption value.

Resource development for sale in a factor market differs markedly from development for own use. Seller development incentives are stronger because buyers bid up resource prices in the hope of preventing resources to be used by their competitor in the product market. As a result, development of resources by sellers in the factor market is always higher than development of resources by buyers $\left(R^{\text {Additive }}>R^{I D}\right)$.

Interestingly, the competitive level of development by buyers $R^{I D}$ is already too high for their own taste. They would be better off developing at a lower level in order to maximize their joint revenues but they are locked in a prisoner's dilemma whereby they develop too much. ${ }^{8}$

Under exclusive combination, the outcome is characterized by the asymmetry of resource development equilibria. ${ }^{9}$ These asymmetric equilibria emerge because a better resource enjoys strictly higher returns than a weaker one, which makes symmetric equilibria untenable.

Thus, resource sellers developing resources competitively can end up choosing different development levels purely as a result of strategic interactions and not because of preexisting asymmetries. ${ }^{10}$

To understand the intuition behind the result, assume that both sellers chose a similar development level. This cannot be an equilibrium because a seller choosing a slightly higher development

\footnotetext{
${ }^{8}$ This is because when they improve their own resource, they undermine their competitor's efficiency (due to $\left.\partial^{2} \Pi^{B}\left(R_{1}, R_{2}\right) / \partial R_{1} \partial R_{2}<0\right)$. However, in a Nash equilibrium, they to not account for this negative effect in their decision making. Having resources developed by sellers in the factor market is only exacerbating this problem.

${ }^{9}$ There is also at least one mixed strategy equilibrium for seller development in this case.

${ }^{10}$ From a technical standpoint, a similar mechanism is operating in Amir and Wooders's (1999, 2000) studies of investment with one-way spillover.
} 
level will immediately enjoy a discrete boost in returns to development. Indeed, the seller's marginal return to development will comprise those from the preemption value $\left(-\Pi^{B}\left(0, \max \left(R_{1}, R_{2}\right)=\right.\right.$ $\left.-\Pi^{B}\left(0, R_{1}\right)>0\right)$ in addition to the use value $\left(\Pi^{B}\left(R_{1}, R_{2}\right)\right)$. Seller $S_{1}$ would then increase its profits by developing the resource even more, motivating the deviation.

In contrast, seller $S_{2}$, now a laggard, only enjoys returns from the use value of its resource because an inferior resource is not worth preempting when combination is exclusive. This effect creates a wedge in development incentives between a leader and a laggard that will make the leader increase its effort and the laggard decrease it. This effect will be compounded by the nature of the strategic interactions between the sellers. Because resource levels are strategic substitutes, the leader's higher development levels are also reducing the development returns of the laggard.

As a result, the lower level of development $R^{L}$ is even less than the development level by buyers $\left(R^{I D}\right)$. This is because the seller developing at a lower level has similar incentives as a buyer, but faces a much more aggressive competitor, which reduces further returns to development.

The last part of the proposition indicates that these results largely hold when the outcome of the factor market is each buyer getting one resource (i.e., if inequality (1) is not satisfied). The main qualification is that resource development by seller will be always more intense than in the integrated development benchmark $\left(R^{A d d *}>R^{I D}\right)$ under the condition that the effect of resource quality has increasing returns $\left(\partial^{2} \Pi^{B}(x, y) / \partial x^{2} \geq 0\right)$. However, this condition is satisfied in most models where resources allow for improvement of quality or reduction of cost, including those in which our assumption that resources are strategic substitutes holds as well (Athey and Schmutzler, 2001).

\section{Alternative timing: CONTRACTING BEFORE RESOURCE DEVELOPMENT}

While resources are often developed before being sold, this is not always the case. A market for contract development of innovation has emerged in the past years. For instance, contract research organizations such as Covance and ICON supply research and development services in the pharmaceutical industry and now make up a substantial part of R\&D expenses in this industry. Similarly, 
Wipro provides extension development services for a range of high tech industries.

A key difference between these markets and those analyzed above is one of timing: development occurs after a contract is concluded. How are our results affected by this change of assumption? Should we expect similar distortions of investment incentives between resource sellers (or contractors) and integrated resource developers?

To answer these questions, I modify the timing of the model and allow buyers to first bid for the exclusive contracting of the development capability of each seller. Once the development capabilities are contracted upon, buyers decide on the development level and assume the costs of development. ${ }^{11}$

Once a buyer has secured access to the development capabilities of a resource buyer, its optimal resource development is not affected by the amount it paid upfront to the seller. This amount is effectively sunk. Given this, we already know from Proposition 2 that the optimal level of resource development is $R^{*}$ in this case. We now only need to consider the development policy in the case where the outcome of the contracting stage is one buyer getting exclusivity from both sellers. Note that this is equivalent to an alternative model where one firm could develop and use two resources while the other could not develop any. The buyers' problem is to find $R_{1}$ and $R_{2}$ that maximize the following profit function:

$$
\Pi^{B}\left(g\left(R_{1}, R_{2}\right), 0\right)-C\left(R_{1}\right)-C\left(R_{2}\right)
$$

From this, it can be shown:

Proposition 3 Assume that development occurs after contracting and that the outcome of the contracting stage is one buyer getting exclusive access to both resource development capabilities.

(i) When resource combination is additive, resource development is symmetric: $R_{1}=R_{2}=$ $R^{A d d * *}$. Moreover, if $\partial^{2} \Pi^{B}(x, y) / \partial x^{2} \geq 0$ then $R^{A d d * *} \geq R^{I D}$. If, in addition, the absolute value of $\partial \Pi^{B}(0, y) / \partial y$ is small relative to $\partial \Pi^{B}(x, 0) / \partial x$, then $R^{\text {Add** }}>R^{\text {Additive }}$.

(ii) When resource combination is exclusive, resource development is asymmetric. One resource is

\footnotetext{
${ }^{11}$ I thank an anonymous referee for suggesting this extension.
} 
developed at level $R^{H * *}$ and the other resource is not developed: $R^{L * *}=0$. We have $R^{H * *}>$ $R^{I D}$. Moreover, if the absolute value of $\partial \Pi^{B}(0, y) / \partial y$ is small relative to $\partial \Pi^{B}(x, 0) / \partial x$, then $R^{H * *}>R^{H}$.

When resources are additive, their combination is not a problem and the buyer develops them symmetrically to equalize the marginal cost of development. If there are increasing returns to owning a better resource $\left(\partial^{2} \Pi^{B}(x, y) / \partial x^{2} \geq 0\right)$, it is necessarily the case that each individual resource is developed at a higher level than $R^{I D}$. If this is true, the returns to development for each resource individually is always at least as high, prompting higher equilibrium development.

There are two forces that influence the level of resource development in this extension. First, returns to development are not undercut by the other seller's resource development as in the base model. This increases the relative returns to development after contract. Second, increasing development level does not increase revenues through the preemption effect as in the base model. Preemption occurred before development decisions are made and does not affect the development decision. This reduces the relative returns to development after contract. When the preemption effect is relatively weak in the baseline model (i.e., $\partial \Pi^{B}(0, y) / \partial y$ is small), the former force dominates the latter and development after contract is higher overall.

Finally, we can precisely delineate under the conditions under which preemption of all resource production capacity will arise.

Proposition 4 Assume that development occurs after contracting. The outcome of the contracting stage is one buyer getting exclusive access to both resource development capabilities if and only if:

$$
\Pi^{B}\left(2 R^{A d d * *}, 0\right)+\Pi^{B}\left(0,2 R^{A d d * *}\right)-2 C\left(R^{A d d * *}\right)>2 \Pi^{B}\left(R^{I D}, R^{I D}\right)-2 C\left(R^{I D}\right) .
$$

if resource combination is additive, or,

$$
\Pi^{B}\left(2 R^{H * *}, 0\right)+\Pi^{B}\left(0,2 R^{H * *}\right)-2 C\left(R^{H * *}\right)>2 \Pi^{B}\left(R^{I D}, R^{I D}\right)-2 C\left(R^{I D}\right)
$$

if resource combination is exclusive. 
As in Proposition 1, the monopolization of production capacity is more likely to happen when industry profits are higher with monopolization of resources. The difference is that the cost of development has to be factored in, as buyers include the cost of developing resource, which they will have to bear, in their calculations.

\section{RESOURCE DEVELOPMENT AND RIVALRY IN THE PRODUCT MARKET}

We have seen above that the eventual allocation of resources (one buyer buying the two, or each buyer getting one) was determined in part by the extent of competitive overlap of buyers in the product market. There are, however, other dimensions to the competitive intensity of an industry. One is the intensity of rivalry (Porter, 1980). Factors such as customer preferences, product differentiation, the ability to connect firms and customers or to collude tacitly can make competition softer or harsher. In this section I investigate how changes in level of rivalry in the product market affect resource development by resource sellers. For conciseness, I restrict the analysis to the case where one buyer ends up with both resources at the conclusion of the factor market competition.

To understand how changes in rivalry intensity affect investments to develop resources, we need to make assumptions on the interaction effect of rivalry and resource quality on product market profits (i.e., the cross partial derivative of $\Pi^{B}$ with respect to rivalry and resource quality). Define $\theta$ as a shifter of the intensity of rivalry in the product market where higher $\theta$ corresponds to higher rivalry.

I make no a priori assumption on the sign of the cross partial of rivalry and own resource quality on product market profits (i.e., the sign of $\partial^{2} \Pi^{B}(x, y, \theta) / \partial \theta \partial x$ can be positive or negative). While it is commonly argued that competitors with better resources should welcome more rivalry (Makadok, 2010; Chatain and Zemsky, 2011), this view is incomplete. Indeed, it is possible for the interaction effect of rivalry and resource quality to be negative even though deploying the resource is still advantageous. This would happen, for instance, when competition in price (Bertrand) while product differentiation is low.

Appendix B presents a numerical example set in a Bertrand differentiated duopoly where $\theta$ stands 
for the effect of a competitor's price on a firm's demand. If $\theta$ is low, then an increase of $\theta$ increases the returns to a resource, while if $\theta$ is high, then a further increase in $\theta$ reduces the returns to the resource. The intuition for this is as follows: in a Bertrand model deploying a resource that reduces marginal cost makes a firm behave more aggressively. Under conditions of high rivalry, this will trigger an aggressive response by the competitor, which undermines the positive effect of deploying the resource. ${ }^{12}$

Finally, I assume that a higher $\theta$ makes a firm more vulnerable to a competitor's resource:

$$
\frac{\partial^{2} \Pi^{B}(x, y, \theta)}{\partial \theta \partial y}<0 .
$$

Based on these assumptions (inequality (5)) we can unpack the effect of rivalry on equilibrium development levels. I will make use of the following definitions:

$$
\begin{aligned}
\text { Use value effect: } & \frac{\partial^{2} \Pi^{B}(x, y, \theta)}{\partial \theta \partial x} \\
\text { Preemption value effect: } & -\frac{\partial^{2} \Pi^{B}(0, g(x, y), \theta)}{\partial \theta \partial y}
\end{aligned}
$$

The use value effect is the interaction effect of rivalry $(\theta)$ and own resource level $(x)$ on profits, because it modifies the returns to deploying a resource for one's own use. The preemption value effect is the opposite of the interaction effect of rivalry $(\theta)$ and competitor's resource level $(y)$, which is the effect of rivalry on the preemption value of a resource. With these definitions, we can study the effect of changes of $\theta$ on equilibrium investment behavior.

Proposition 5 Assume that the outcome of the sales is one buyer acquiring both resources and consider the effect of small changes in rivalry (parameter $\theta$ ) on equilibrium development levels, starting from $\theta_{0}$. If resource combination is additive:

1. $\partial R^{\text {Additive }} / \partial \theta>0$ when the sum of the interaction effects of rivalry and resource development on use value and on preemption value is positive.

\footnotetext{
${ }^{12}$ This is consistent with the results offered by Almeida Costa, Cool and Dierickx (2012). They show that when competition is on price, and rivalry is very high, deploying a value-enhancing resource can even have a negative effect on the profits of the firm deploying the resource because of the escalation of rivalry in the product market.
} 
2. A change in rivalry parameter can have opposite effects on equilibrium development levels if development is by sellers before the sale rather than by buyers or by sellers after a contract. This is the case when the interaction effect of rivalry and resource development on use value is negative while the total effect on use and preemption value is positive.

The first point of the proposition implies that more rivalry will entail more resource development by sellers unless there is a strong negative interaction effect of rivalry and own resource levels on product market profits. Indeed, given that $\left.\partial^{2} \Pi^{B}(x, y, \theta) / \partial \theta \partial y<0\right)$, by assumption it takes a very negative interaction effect on the use value to decrease the returns to resource development. This confirms the impression that competition in the product market tends to be bad for resource buyers. More rivalry is simply making the preemption value of resources higher, implying that resource sellers will develop more than what resource buyers would.

This is confirmed by the second point of the proposition. In fact, if the effect of more competition on use value is negative but is dominated by the effect on preemption value, we can even see opposite effects. What's more, we can see similar effects at play when resource combination is exclusive:

Proposition 6 If resource combination is exclusive, equilibrium development levels can be moving in opposite directions $\left(\partial R^{H} / \partial \theta>0\right.$ while $\left.\partial R^{L} / \partial \theta<0\right)$ if the effect of more rivalry on use value is negative while the combination of the effect on use value and preemption value is positive.

When resource combination is exclusive, more competition can unambiguously exacerbate the gap between high $\left(R^{H}\right)$ and low $\left(R^{L}\right)$ development levels. This result stresses the complex interactions between product market competition, strategic factor market and resource combination.

\section{DISCUSSION AND CONCLUSION}

The relationship between determinants of value capture in the product market and resource value in the factor market has been an open issue for resource-based theorists. They have made great strides in understanding how rivalry in the product market affects the value resources can capture (Chatain and Zemsky, 2011; Grahovac and Miller, 2009; Makadok, 2010). However, how product 
market rivalry affects resource prices, and thus resource development, on factor markets has not been formally explored so far. This issue is of import for resource-based theorists as we know comparatively little about the determinants of the supply of resources to factor markets.

This paper tackles this challenge by analyzing resource development while modeling competition in the both the strategic factor market and the product market. This symmetric treatment of competition allows uncovering relationships between constructs that were not previously analyzed together (Foss and Hallberg, 2013). Specifically, we now have a starting point for developing theory linking rivalry and value capture in the product market to the supply of resources in the strategic factor market.

\section{Implications for empirical research}

Thanks to this framework, researchers will be able to better specify empirical studies of resource acquisition and resource development and test new hypotheses.

Proposition 1 shows that the combined value of resources and the extent of competitive overlap in the product market jointly determine resource prices and resource concentration. It alerts empirical researchers to control for both product market characteristics and the nature of resource combination when studying the outcome of strategic factor market competition. For instance, while studies of resource acquisition routinely examine the combined value of a target with a potential acquirer, they tend to consider each acquisition in isolation and not to look at the combination value of several targets together. Yet Proposition 1 shows that how targets may combine with each other influences the eventual outcome of sales in the strategic factor market.

Proposition 2 suggests that, ceteris paribus, resource development patterns are qualitatively different in cases where resource development and deployment are separated and resources are sold to a factor market relative to cases where resource development and deployment are integrated. When the allocation of resources is the outcome of the operations of a strategic factor market, the model suggests that resource development tends to be more intense. Moreover, when resource combination is exclusive, equilibrium development will be asymmetric and resources supplied on the factor market will be heterogeneous even though suppliers of resources were initially symmetric. 
Such proposition can be empirically tested by following a research design similar to the one used by Murray and colleagues' (2009) study of open innovation and research outcomes. The idea is to use a difference-in-differences approach to compare two parts of the same industry, with one where the strategic factor market is shut down (or open) for exogenous reasons (e.g., changes in regulation) and the other one serving as a control group.

Another implication is that, if resources acquired were overdeveloped to start with, buyers will tend to do little to upgrade them once the acquisition is completed. In the case of a purely preemptive acquisition, it means that the resources acquired will be simply left unused. Both of these patterns have been observed in high technology contexts. For instance, Santos and Eisenhardt (2009) document the acquisition of a technology startup firm followed by a shut down because the main motivation for the acquisition was preemptive. There are also many recent examples of acquisition of startups followed by service shutdown. This is such a well-known issue that when startup Simperium was acquired in January 2013, its management felt necessary to post the following message, mentioning both shutdowns and lack of investment, on their website: "You know how sometimes, the services you love just disappear when they're bought by someone else? Or they wither and die a slow and painful death? Not the case here. We made sure of that."13

These shutdowns are sometimes construed as acquisition mistakes, failure of integration, or seen as reflecting the fact that buyers were more interested in the team than in the product ("acquihires"). This paper's framework provide a different rationale: the features that were created by the seller and then shut down by the acquirer were developed to extract a high price in the strategic factor market but were excessive relative to the actual needs of the acquirer.

The acquisitions of startups AdMob and Quattro in late 2009 by respectively Google and Apple combines several of the ingredients of the model in a way consistent with Propositions 1 and 2. Both startups were operating in a similar technological space (mobile advertising) and were developing similar capabilities. Their combination would have likely been exclusive as the knowledge assets and know-how they developed are similar. Moreover, Apple and Google seemed acutely aware that

\footnotetext{
${ }^{13}$ Quote from http://simplenote.com/2013/01/24/simplenote-supercharged/, retrieved June 21, 2013. For an extensive list of shutdowns post-acquisition (38 as of June 2013), see http:// ourincrediblejourney.tumblr.com/.
} 
a move to acquire one of these startups would negatively affect the other in the product market: after Google acquired AdMob, Steve Jobs complained that Google bought AdMob because “they didn't want us to have them."14

Industry observers noted that rivalry between Apple and Google in the startup acquisition market mirrored increased rivalry in the mobile service product market. The two acquisitions were contemporaneous (November 2009 for Admob and January 2010 for Quattro) and perceived as part a continuing competitive interaction. Industry observers also agreed that the two startups differed in quality, which was reflected in their respective price tags (a reported $\$ 750$ million for AdMob, a rumored \$250million for Quattro). In the frame of this model, the exclusive nature of the resources may have driven the outcome of the factor market competition as suggested by Proposition 1 as well as the heterogeneity of the development efforts before the acquisition according to Proposition 2. After the acquisition, Quattro's activities were shut down while AdMob's founder left Google almost a year after the acquisition among rumors that post-merger integration was difficult ${ }^{15}$

Propositions 3 and 4 imply that in the case of contracting before development, multiple contingencies need to be controlled to explain the intensity of resource development. When resource combination is exclusive, we may observe the shutdown of some projects $\left(R^{L * *}=0\right)$ even though they were technically sound. Other factors such as synergies in benefits from resources (from the convexity of the first argument of $\Pi^{B}$ ) will also matter and are likely to differ across markets. Finally, the negative effect of a competitor's resources (the absolute value of $\partial \Pi^{B}(0, y) / \partial y$ ) will also need to be accounted for in order to compare resource development for sale to resource development under contract.

Finally, Propositions 5 and 6 show that variation in rivalry levels in the product market can have a significant impact on the supply of resources in the factor market. If rivalry changes over time, then the incentives to develop resources will also change but differently for integrated developers and for specialized developers. When the combination of resources is exclusive, we may also see

\footnotetext{
${ }^{14}$ Remarks by Steve Jobs recorded at the iPhone OS 4.0 Launch event, April 8, 2010, Cupertino, CA. Steve Jobs jabs at Google Android, AdMob. YouTube Video: http://www.youtube.com/watch?v=V5XXEisgzdo, retrieved May 14, 2010.

${ }^{15}$ Jay Yarow, "Google's AdMob Integration Is 'Just Not Going Great' ”, Business Insider, November 1, 2010, http: //www.businessinsider.com/admob-google-2010-11, retrieved June 21, 2013.
} 
an increase in the heterogeneity of the resources that are offered for sale. This suggests to exploit exogenous changes in product market rivalry (e.g., changes in competitive frictions) to empirically test these propositions, by looking at development conduct before and after the shock in an industry, while carefully constructing a comparison group not affected by the shock to use a difference-indifferences estimator.

\section{Implications for practitioners}

Resource sellers - e.g., startup entrepreneurs, small biotechnology companies - can draw a few insights from these results. If sellers can choose their buyers, they should not simply look for buyers who have a need for the resource. They should also identify buyers that are locked in tight competitive contests - facing competitors head-to-head in a high rivalry environment. ${ }^{16}$ Resource sellers also have a clear interest in fueling rivalry between potential buyers. This can be achieved through political strategies, for instance. One can imagine resource sellers covertly helping consumer groups lobby to make a product market more competitive.

Moreover, sellers may want to make sure that their resources can be combined relatively smoothly with comparable resources that are developed concurrently. Resources that are inferior and incompatible command lower prices because of their lower marginal contribution.

From the viewpoint of resource buyers, options may seem more limited. Unless they can contract with sellers before development, the resources will be overdeveloped and overpriced. Even if they can contract beforehand and get resources of the quality they prefer, sellers will still be able to extract significant rents. This suggests that buyers may want to insulate themselves from factor markets in order to avoid being squeezed by resource sellers. To credibly do so, they might invest to develop their own development capabilities even if they are comparatively less efficient.

Ironically, relying on strategic factor markets to procure resources may be a riskier endeavor than previously thought. It is well understood that factor markets may not give the opportunity for easy economic profit (Barney, 1986). However, buyers of resources may be even more vulnerable when

\footnotetext{
${ }^{16}$ This is reminiscent of Rumelt's (2011: 227) argument that innovations that help their users win competitions are adopted faster.
} 
they are competing with each other in the product market (Asmussen, 2010). Buyers may want to mitigate those risks by fostering more competition among sellers, for instance by subsidizing entry on the supply side of factor markets.

\section{Directions for future research}

Future research can seek to analyze jointly the interaction of other key features of strategic factor markets, product market competition as well as the process of resource accumulation. As argued by Maritan and Peteraf (2011) resource acquisition and accumulation are deeply intertwined processes that scholars have tended to study separately mainly for analytical convenience. In the same vein, the internal organization of the firm has been shown to interact with rivalry in both factor markets (Ross, 2012) and product markets (Sengul and Gimeno, 2013; Vroom, 2006) but we know little about the tradeoffs involved with simultaneously organizing for rivalry in both types of markets.

Another approach to explore is to model interactions in the factor market in a cooperative game framework (Lippman and Rumelt, 2003; MacDonald and Ryall, 2004; Brandenburger and Stuart, 1996, 2007). The potential emptiness of the core when there are externalities creates a hurdle, but the greater generality of that approach might offer additional insights. Moreover, the outcome of non-cooperative models of negotiation in the supply chain can sometimes be subsumed into a cooperative game framework (e.g., de Fontenay and Gans, 2005).

The model could also be extended to include other actions by sellers, including the decision to enter the market. Ghemawat (1990) shows that a dominant firm can keep buying whatever production capacity is offered, depriving competitors of the opportunity to extend operations, but Krishna (1993) suggests that other contingencies may reverse that result. Allowing for sequential entry in conjunction with resource development and various resource integration scenarios would give us a more comprehensive picture of competition in the factor market. Other relevant actions include the horizontal differentiation of resources and the specialization of resources to specific product markets. Another line of inquiry is to explore the links between competition for factors and competition for political influence (Capron and Chatain, 2008). If resource preemption matters to development, actions in the political market, where regulations are determined, should also play a role. 


\section{REFERENCES}

Adegbesan T, 2009. On the origins of competitive advantage: Strategic factor markets and heterogeneous resource complementarity. Academy of Management Review 34(3): 463-475.

Adner R, Zemsky P, 2006. A demand-based perspective on sustainable competitive advantage. Strategic Management Journal 27(3): 215-239.

Amir R, Garcia F, Knauff M, 2010. Symmetry-breaking in two-player games via strategic substitutes and diagonal nonconcavity: A synthesis. Journal of Economic Theory 145(5): 1968-1986.

Amir R, Wooders J, 1999. Effects of One Way spillovers on market shares, industry price, welfare, and R\&D cooperation. Journal of Economics \& Management Strategy 8(2): 223-249.

Amir R, Wooders J, 2000. One-Way spillovers, endogenous Innovator/Imitator roles, and research joint ventures. Games and Economic Behavior 31(1): 1-25.

Anton JJ, Yao DA, 1994. Expropriation and inventions: Appropriable rents in the absence of property rights. The American Economic Review 84(1): pp. 190-209.

Arora A, Fosfuri A, 2003. Licensing the market for technology. Journal of Economic Behavior \& Organization 52(2): 277-295.

Arrow K, 1962. Economic welfare and the allocation of resources for invention. NBER 609-626.

Asmussen CG, 2010. Chicken, stag, or rabbit? strategic factor markets and the moderating role of downstream competition. Atlanta Competitive Advantage Conference 2010 Paper (Available at SSRN: http://ssrn.com/abstract=1550727).

Athey S, Schmutzler A, 2001. Investment and market dominance. RAND Journal of Economics 32(1): 1-26.

Barney JB, 1986. Strategic factor markets: Expectations, luck, and business strategy. Management Science 32(10): 1231-1241.

Barney JB, 1988. Returns to bidding firms in mergers and acquisitions: Reconsidering the relatedness hypothesis. Strategic Management Journal 9(Special Issue): 71-78, summer.

Brandenburger A, Stuart H, 2007. Biform games. Management Science 53(4): 537-549.

Brandenburger A, Stuart Jr H, 1996. Value-based business strategy. Journal of Economics \& Management Strategy 5(1): 5-24.

Burgelman RA, Meza PE, 2004. HP and compaq combined: In search of scale and scope. Stanford GSB (SM-130).

Cachon GP, Harker PT, 2002. Competition and outsourcing with scale economies. Management Science 48(10): 1314-1333.

Capron L, Chatain O, 2008. Competitors' resource-oriented strategies: Acting upon competitors' resources through interventions in factor markets and political markets. Academy of Management Review 33(1): 97-121.

Capron L, Mitchell W, 2009. Selection capability: How capability gaps and internal social frictions affect internal and external strategic renewal. Organization Science 20(2): 294-312.

Cassiman B, Colombo MG, Garrone P, Veugelers R, 2005. The impact of M\&A on the R\&D process: An empirical analysis of the role of technological- and market-relatedness. Research Policy 34(2): 195220.

Chatain O, Zemsky P, 2011. Value creation and value capture with frictions. Strategic Management Journal 32(11): 1206-1231.

Chaudhuri S, Tabrizi B, 1999. Capturing the real value in high-tech acquisitions. Harvard business review 77(5): 123-130, 185, PMID: 10621263. 
Costa LA, Cool K, Dierickx I, 2012. The competitive implications of the deployment of unique resources. Strategic Management Journal n/a-n/a.

de Fontenay CC, Gans JS, 2005. Vertical integration in the presence of upstream competition. The RAND Journal of Economics 36(3): pp. 544-572.

Denrell J, Fang C, Winter SG, 2003. The economics of strategic opportunity. Strategic Management Journal 24(10): 977-990.

Dierickx I, Cool K, 1989. Asset stock accumulation and sustainability of competitive advantage. Management Science 35(12): 1504-1514.

Foss NJ, Hallberg NL, 2013. How symmetrical assumptions advance strategic management research. Strategic Management Journal n/a-n/a.

Gabszewicz JJ, Zanaj S, 2008. Upstream market foreclosure. Bulletin of Economic Research 60(1): 13-26.

Gans JS, Stern S, 2000. Incumbency and R\&D incentives: Licensing the gale of creative destruction. Journal of Economics \& Management Strategy 9(4): 485-511.

Ghemawat P, 1990. The snowball effect. International Journal of Industrial Organization 8(3): 335-351.

Gilbert SM, Xia Y, Yu G, 2006. Strategic outsourcing for competing oems that face cost reduction opportunities. IIE Transactions 903-915.

Graebner ME, 2004. Momentum and serendipity: how acquired leaders create value in the integration of technology firms. Strategic Management Journal 25(8-9): 751-777.

Grahovac J, Miller DJ, 2009. Competitive advantage and performance: the impact of value creation and costliness of imitation. Strategic Management Journal 30(11): 1192-1212.

Gupta S, Loulou R, 1998. Process innovation, product differentiation, and channel structure: Strategic incentives in a duopoly. Marketing Science 17(4): 301-316.

Hirshleifer J, 1980. Price theory and applications. Prentice-Hall, Englewood Cliffs, N.J, 2d ed ed.

Jehiel P, Moldovanu B, 1996. Strategic nonparticipation. Rand Journal of Economics 27(1): 84-98, spring.

Kogut B, Zander U, 1992. Knowledge of the firm, combinative capabilities, and the replication of technology. Organization Science 3(3): 383-397.

Kor YY, Mahoney JT, 2000. Penrose's resource-based approach: The process and product of research creativity. Journal of Management Studies 37(1): no-no.

Kor YY, Mahoney JT, 2005. How dynamics, management, and governance of resource deployments influence firm-level performance. Strategic Management Journal 26(5): 489-496.

Krishna K, 1993. Auctions with endogenous valuations: The persistence of monopoly revisited. The American Economic Review 83(1): pp. 147-160.

Krishna V, 2009. Auction theory. Academic press, 2d ed.

Levinthal DA, Wu B, 2010. Opportunity costs and non-scale free capabilities: profit maximization, corporate scope, and profit margins. Strategic Management Journal 31(7): 780-801.

Mahoney JT, Pandian JR, 1992. The resource-based view within the conversation of strategic management. Strategic Management Journal 13(5): 363-380.

Makadok R, 2001. Toward a synthesis of the resource-based and dynamic-capability views of rent creation. Strategic Management Journal 22(5): 387-401.

Makadok R, 2010. The interaction effect of rivalry restraint and competitive advantage on profit: Why the whole is less than the sum of the parts. Management Science 56(2): 356-372.

Makadok R, Barney JB, 2001. Strategic factor market intelligence: An application of information economics to strategy formulation and competitor intelligence. Management Science 47(12): 1621-1638. 
Maritan CA, Florence RE, 2008. Investing in capabilities: bidding in strategic factor markets with costly information. Managerial and Decision Economics 29(2-3): 227-239.

Maritan CA, Peteraf MA, 2011. Invited editorial: Building a bridge between resource acquisition and resource accumulation. Journal of Management 37(5): 1374-1389.

Murray F, Aghion P, Dewatripont M, Kolev J, Stern S, 2009. Of mice and academics: Examining the effect of openness on innovation. Working Paper 14819, National Bureau of Economic Research.

Pacheco-de-Almeida G, Zemsky P, 2007. The timing of resource development and sustainable competitive advantage. Management science 53(4): 651-666.

Penrose ET, 1959. The Theory of the Growth of the Firm. Oxford University Press.

Peteraf MA, Barney JB, 2003. Unraveling the resource-based tangle. Managerial and Decision Economics 24(4): 309-323.

Porter ME, 1980. Competitive strategy: techniques for analyzing industries and competitors. Free Press, New York.

Priem RL, 2007. A consumer perspective on value creation. Academy of Management Review 32(1): 219-235.

Priem RL, Butler JE, 2001. Is the Resource-Based "View" a useful perspective for strategic management research? The Academy of Management Review 26(1): 22-40.

Puranam P, Singh H, Chaudhuri S, 2009. Integrating acquired capabilities: When structural integration is (un)necessary. Organization Science 20(2): 313-328.

Ranft AL, Lord MD, 2002. Acquiring new technologies and capabilities: A grounded model of acquisition implementation. Organization Science 13(4): 420-441.

Rey P, Tirole J, 2007. Chapter 33: A primer on foreclosure. In Handbook of Industrial Organization, M Armstrong, R Porter, eds., vol. Volume 3, 2145-2220, Elsevier.

Ross D, 2012. On evaluation costs in strategic factor markets: The implications for competition and organizational design. Management Science 58(4): 791-804.

Ruiz-Aliseda F, Zemsky PB, 2006. Adoption is Not Development: First Mover Advantages in the Diffusion of New Technology. SSRN eLibrary .

Rumelt RP, 2011. Good Strategy, Bad Strategy: The Difference and Why It Matters. Random House Digital, Inc.

Ryall M, MacDonald G, 2004. How do value creation and competition determine whether a firm appropriates value? Management Science 50(10): 1319-1333.

Salop SC, Scheffman DT, 1983. Raising rivals' costs. The American Economic Review 73(2): 267-271.

Santos FM, Eisenhardt KM, 2009. Constructing markets and shaping boundaries: Entrepreneurial power in nascent fields. Academy of Management Journal 52(4): 643-671.

Schelling TC, 1960. The Strategy of Conflict. Harvard University Press, Cambridge, Massachusetts.

Sengul M, Gimeno J, 2013. Constrained delegation: Allocation of decision rights and resources in firms that compete across multiple industries. Administrative Science Quarterly 58(3).

Stahl II DO, 1988. Bertrand competition for inputs and walrasian outcomes. American Economic Review 78(1): 189.

Topkis DM, 1998. Supermodularity and complementarity. Princeton University Press, Princeton, NJ.

Van Zandt T, 2002. An introduction to monotone comparative statics. INSEAD Working Paper.

Vives X, 1999. Oligopoly Theory. MIT Press, Cambrige MA. London.

Vroom G, 2006. Organizational design and the intensity of rivalry. Management Science 52(11): 1689-1702. 


\section{APPENDIX A: PROOFS}

The proofs often rely on monotone comparative statics techniques. For an introduction to monotone comparative statics from an applied modeler point of view, see Van Zandt (2002); for applications to oligopoly theory see Vives (1999); for a more general treatment see Topkis (1998).

\section{Proof of Proposition 1}

Role of inequality (1) Summing up $b_{1}^{1}>b_{1}^{2}$ and $b_{2}^{1}>b_{2}^{2}$ as expressed in the text and simplifying yields inequality (1). Thus, if inequality (1) is satisfied both resources are acquired by the same buyer. For sufficiency, assume that each buyer buys one resource. The bids for resource $R_{1}$, assuming that resource $R_{2}$ goes to buyer $B_{2}$, are as follows:

$$
b_{1}^{1}=\Pi^{B}\left(R_{1}, R_{2}\right)-\Pi^{B}\left(0, g\left(R_{1}, R_{2}\right)\right), \quad b_{2}^{1}=\Pi^{B}\left(g\left(R_{1}, R_{2}\right), 0\right)-\Pi^{B}\left(R_{2}, R_{1}\right) .
$$

Conversely, the bids for resource $R_{2}$, assuming that resource $R_{1}$ goes to buyer $S_{1}$, are:

$$
b_{1}^{2}=\Pi^{B}\left(g\left(R_{1}, R_{2}\right), 0\right)-\Pi^{B}\left(R_{1}, R_{2}\right), \quad b_{2}^{2}=\Pi^{B}\left(R_{2}, R_{1}\right)-\Pi^{B}\left(0, g\left(R_{1}, R_{2}\right)\right) .
$$

These bids form an equilibrium whereby each buyer gets one resource if $b_{1}^{1} \geq b_{2}^{1}$ and $b_{1}^{2} \leq b_{2}^{2}$. Summing inequalities $b_{1}^{1} \geq b_{2}^{1}$ and $b_{1}^{2} \leq b_{2}^{2}$ gives:

$$
\Pi^{B}\left(R_{1}, R_{2}\right)+\Pi^{B}\left(R_{1}, R_{2}\right) \geq \Pi^{B}\left(g\left(R_{1}, R_{2}\right), 0\right)+\Pi^{B}\left(0, g\left(R_{1}, R_{2}\right)\right),
$$

which is equivalent to inequality (1) not holding.

Thus, if inequality (1) holds only one buyer buying the two resources can be an equilibrium. A similar reasoning can be followed to show the converse claims.

Identity of the resource acquirers Because, by assumption, buyers $B_{1}$ and $B_{2}$ have similar valuations their roles are interchangeable in each type of equilibrium.

\section{Proof of Proposition 2}

Development by buyers: existence, symmetry, comparison with industry profit maximizing development Buyer's $i$ objective function is $\Pi_{i}\left(R_{i}, R_{-i}\right)-C\left(R_{i}\right)$. This function is submodular in $\left(R_{i}, R_{-i}\right)$ and the development game is thus submodular. By a change of variable, a two-player submodular game can be transformed into a supermodular game. A supermodular game always admits at least one pure strategy Nash equilibrium (Vives, 1999). Because of the symmetry of the payoff functions, the best response functions are symmetric as well. Because payoffs are twice continuous differentiable, the best response is continuous as well. Thus a symmetric interior PSNE $\left(R^{I D}, R^{I D}\right)$ exists.

Development by sellers: Existence Seller $S_{i}$ 's objective function is: $\Pi_{i}^{S}\left(R_{i}\right)=\Pi^{B}\left(R_{i}, R_{-i}\right)-$ $\Pi^{B}\left(0, g\left(R_{i}, R_{-i}\right)\right)-C\left(R_{i}\right)$. This function is the sum of a strictly submodular function $\left.\left(\Pi^{B}\left(R_{i}, R_{-i}\right)\right)\right)$ and of $-\Pi^{B}\left(0, g\left(R_{i}, R_{-i}\right)\right)$ which is itself submodular. Indeed, by Lemma 2.6.4 of Topkis (1998: 56), a decreasing convex transformation of an increasing submodular function is supermodular. The function $g\left(R_{i}, R_{-i}\right)$ is trivially submodular when it is additive or takes the maximum of its two arguments, and the second argument of $\Pi^{B}(.,$.$) is convex by assumption. Consequently \Pi^{B}\left(0, R_{i}+R_{-i}\right)$ is supermodular, which implies that $-\Pi^{B}\left(0, R_{i}+R_{-i}\right)$ is submodular. The objective function is the sum of strictly submodular function and of a submodular function and thus submodular. Thanks to this the development game is submodular. By a change of variable, a two-player submodular game can be transformed into a supermodular game. A supermodular game always admits at least one pure strategy Nash equilibrium (Vives, 1999). 
Symmetric equilibrium with additive resource combination when resources are bought by one buyer Because of the symmetry of the payoff functions, the best response functions are symmetric as well. Because payoffs are twice continuous differentiable, the best response is continuous as well. Thus a symmetric interior PSNE ( $\left.R^{\text {Additive }}, R^{\text {Additive }}\right)$ exists.

Asymmetric equilibrium with exclusive resource combination when resources are bought by one buyer I use theorem Theorem 3.1 by Amir, Garcia and Knauff (2010: 1973) to show the existence of asymmetric PNSEs and non-existence of symmetric PSNEs with exclusive resource combination. We have already shown that $\Pi^{S}$ was submodular. The key pre-condition to be shown is that the payoff function $\Pi^{S}(x, y)$ can be split in two different components, $U(x, y)$ if $x \geq y$ and $L(x, y)$ if $x<y$. Let:

$$
\begin{aligned}
U(x, y) & =\Pi_{i}^{S}(x, y) \text { if } x \geq y \\
& =\Pi^{B}(x, y)-\Pi^{B}(0, x)-C(x), \\
L(x, y) & =\Pi_{i}^{S}(x, y) \text { if } x<y \\
& =\Pi^{B}(x, y)-\Pi^{B}(0, y)-C(x) .
\end{aligned}
$$

Because $\partial-\Pi^{B}(0, x) / \partial x>0$ and $\partial-\Pi^{B}(0, y) / \partial x=0$, it is the case that the derivative from the right of $U(x, x)$ in its first argument is strictly more than the derivative from the left of $L(x, x)$ in its first argument, as stated by Amir, Garcia and Knauff (2010: 1973).

Moreover, because of the strict concavity of $C($.$) , there exists a level of development R^{c}$ such that $V^{H}<0$ for any development levels $\left(R^{c}, R_{-j}\right.$. This rules out $R_{j}>R^{c}$ as being part of any best response and $\left(R^{c}, R^{c}\right)$ as an equilibrium. We can restrict the strategy space to $R_{j}<c$ by defining $c=R^{c}$.

Similarly, because of our assumptions on $C($.$) , it is always beneficial to develop the resource at a strictly$ positive level $R_{j}>0$ regardless of the level of $R_{-j}$. This rules out $(0,0)$ as an equilibrium and we can restrict our attention to strictly positive strategies.

Thanks to the above, all conditions for Theorem 3.1 by Amir, Garcia and Knauff (2010: 1973) are checked. It implies that no symmetric PSNE exists, and that at least one asymmetric PSNE exists.

Relative development levels Proof technique The method for the proof consists in showing that the best response functions of the players in one game (the buyer resource development game) are always lower than the other game (the seller resource development game). This implies that the symmetric equilibrium point, which is where the best response function crosses the 45 degree line, of the former game is necessarily attained for a lower level of resource development than in the latter game.

Proof of $R^{\text {Additive }}>R^{I D}$. In the integrated development game, Buyer $B_{i}$ 's objective function is $\Pi_{i}\left(R_{i}, R_{-i}\right)-C\left(R_{i}\right)$. In the factor market development game, seller $S_{i}$ 's objective function is $\Pi_{i}\left(R_{i}, R_{-i}\right)-$ $\Pi^{B}\left(0, R_{i}+R_{-i}\right)-C\left(R_{i}\right)$. We have $-\partial \Pi^{B}\left(0, R_{i}+R_{-i}\right) / \partial R_{i}>0$, so the marginal return to development by a seller is always strictly more than that of a buyer given $R_{-i}$. This implies, by the principle of monotone comparative statics, that a seller's best response to $R_{-i}$ is always at a higher level than a buyer's. This, combined with the symmetry of the product functions, means that the best response function of the seller will cross the 45 degree line (such that $B R^{S}(x)=x$ )for a value of development that is strictly higher that the corresponding value for the buyer. Thus $R^{\text {Additive }}>R^{I D}$.

Proof of $R^{H}>R^{I D}>R^{L}$. The objective function of a low level developer is $\Pi_{i}\left(R_{i}, R_{-i}\right)-\Pi^{B}\left(0, R_{-i}\right)-$ $C\left(R_{i}\right)$ which exhibit the same marginal returns to development at the objective function of a buyer. This implies that their best response functions are identical wherever their domain corresponds. Let $B R(x)$ the best response function of the buyer. By assumption, we have $R^{H}>R^{L}$, but by definition of the asymmetric equilibrium $B R\left(R^{H}\right)=R^{L}<R^{H}$. To study the possible values of $R^{L}$ we can thus restrict our attention to the domain where $B R(x)<x$. Moreover by definition of the symmetric integrated development equilibrium, 
we have $B R\left(R^{I D}\right)=R^{I D}$. But, because of the assumption of strategic substitutability in resource levels and on differentiability, this function is decreasing and continuous over its domain. This implies that $R^{I D}$ is an upper bound of any value that $R^{L}$ may take. Thus $R^{I D}>R^{L}$.

The objective function of a seller developing at a high level with exclusive resource combination is $\Pi_{i}\left(R_{i}, R_{-i}\right)-\Pi^{B}\left(0, R_{i}\right)-C\left(R_{i}\right)$. We have $-\partial \Pi^{B}\left(0, R_{i}\right) / \partial R_{i}>0$, so the marginal return to development by a seller is always strictly more than that of a buyer given $R_{-i}$. This implies, by the principle of monotone comparative statics, that a high level seller's best response to $R_{-i}$ is always at a higher level than a buyer's. We also know that the low level developer equilibrium strategy is less than that $R^{I D}$. This implies $R^{H}>R^{I D}$.

Symmetry of development in the additive case when resources are bought by different buyers The first order conditions for a Nash equilibrium in resource development are:

$$
\begin{aligned}
& \frac{\partial \Pi_{1}^{S}}{\partial R_{1}}=\frac{\partial \Pi^{B}\left(R_{1}+R_{2}, 0\right)}{\partial R_{1}}-\frac{\partial \Pi^{B}\left(R_{2}, R_{1}\right)}{\partial R_{1}}-\frac{\partial C\left(R_{1}\right)}{\partial R_{1}}, \\
& \frac{\partial \Pi_{2}^{S}}{\partial R_{2}}=\frac{\partial \Pi^{B}\left(R_{1}+R_{2}, 0\right)}{\partial R_{2}}-\frac{\partial \Pi^{B}\left(R_{1}, R_{2}\right)}{\partial R_{2}}-\frac{\partial C\left(R_{2}\right.}{\partial R_{2}} .
\end{aligned}
$$

These are symmetric, and by our assumptions on $\Pi^{B}$ and $C$ best responses functions are also continuous. There exists thus a symmetric equilibrium.

Asymmetry of development in the exclusive combination case when resources are bought by different buyers The first order conditions for a Nash equilibrium in resource development, are:

$$
\begin{aligned}
& \frac{\partial \Pi^{S}}{\partial R_{i}}=\frac{\partial \Pi^{B}\left(R_{i}, 0\right)}{\partial R_{i}}-\frac{\partial \Pi^{B}\left(R_{-i}, R_{i}\right)}{\partial R_{i}}-\frac{\partial C\left(R_{i}\right)}{\partial R_{i}} \text { if } R_{i}>R_{-i}, \\
& \frac{\partial \Pi^{S}}{\partial R_{i}}=-\frac{\partial \Pi^{B}\left(R_{i}, R_{-i}\right)}{\partial R_{i}}-\frac{\partial C\left(R_{i}\right.}{\partial R_{i}} \text { if } R_{i} \leq R_{-i} .
\end{aligned}
$$

There is a discontinuity in the returns at $R_{i}=R_{-i}$, where a slight increase in $R_{i}$ brings a full $\frac{\partial \Pi^{B}\left(R_{i}, 0\right)}{\partial R_{i}}$ of additional marginal returns. This implies that $R_{i}=R_{-i}$ cannot be an equilibrium as each seller has an incentive to deviate. Then, they cannot be any symmetric equilibrium since best response functions are discontinuous at $R_{j}=R_{-j}$. The development levels $R^{H *}$ and $R^{L *}$ are the solutions to the system of equations (6)-(7).

Relative development levels when resources are bought by different buyers Proof of $R^{H *}>$ $R^{I D}$. The profit function of the high development seller given the competitor's action $R_{-i}$ is: $\Pi^{S}=$ $\Pi^{B}\left(R_{i}, 0\right)-\Pi^{B}\left(R_{-i}, R_{i}\right)-C\left(R_{i}\right)$. The marginal returns to increasing $R_{i}$ are always strictly higher than those of a buyer as: $\frac{\partial \Pi^{B}\left(R_{i}, 0\right)}{\partial R_{i}}>\frac{\partial \Pi^{B}\left(R_{i}, R_{-i}\right.}{\partial R_{i}}$ for $R_{-i}>0$ by the assumption on strategic substitutability and $\frac{\partial-\Pi^{B}\left(R_{-i}, R_{i}\right)}{\partial R_{i}}>0$. This implies that for any $R_{-i}$ the best response of the seller is larger than that of the buyer. Thus $R^{H *}>R^{I D}$ Proof of $R^{\text {Additive* }}>R^{I D}$. Consider the following profit function:

$$
\Pi^{S}=\Pi^{B}\left(R_{i}, R_{-i}\right)-C\left(R_{i}\right)+\mathbf{1}_{\text {Additive }} \cdot\left[-\Pi^{B}\left(R_{i}, R_{-i}\right)+\Pi^{B}\left(R_{i}+R_{-i}, 0\right)-\Pi^{B}\left(R_{-i}, R_{i}\right)\right]
$$

If $\mathbf{1}_{\text {Additive }}=0$ then this function is equal to the profit function of a buyer developing a resource. If If $\mathbf{1}_{\text {Additive }}=1$ then it is equal to that of a seller in the additive case. Following the principle of monotone comparative statics, we only need to prove increasing differences in $\mathbf{1}_{\text {Additive }}$ and $R_{i}$ in order to show 
$R^{\text {Additive* }}>R^{I D}$. This boils down to:

$$
-\frac{\partial \Pi^{B}\left(R_{i}, R_{-i}\right)}{\partial R_{i}}+\frac{\partial \Pi^{B}\left(R_{i}+R_{-i}, 0\right)}{\partial R_{i}}-\frac{\partial \Pi^{B}\left(R_{-i}, R_{i}\right)}{\partial R_{i}}>0 .
$$

But $-\frac{\partial \Pi^{B}\left(R_{-i}, R_{i}\right)}{\partial R_{i}}>0$ and $\Pi^{B}$ exhibits strategic substitutability. A sufficient condition for this condition to be met is $\partial^{2} \Pi^{B}(x, y) / \partial x^{2}>0$ which guarantees $\frac{\partial \Pi^{B}\left(R_{i}+R_{-i}, 0\right)}{\partial R_{i}}>\frac{\partial \Pi^{B}\left(R_{i}, R_{-i}\right)}{\partial R_{i}}$ for any $R_{-i} \geq 0$.

\section{Proof of Proposition 3}

(i) The profit function to be maximized (not accounting for transfers to the sellers, which are sunk) is:

$$
\Pi^{B}\left(R_{1}+R_{2}, 0\right)-C\left(R_{1}\right)-C\left(R_{2}\right) .
$$

The first order conditions do not entail corner solutions due to our assumptions on the shape of $\Pi^{B}$ and $C$. The optimal development levels are thus symmetric.

(ii) Suppose that optimal development levels are, without loss of generality $R_{1} \geq R_{2}$ with $R_{2}>0$. Then the profit of the buyer (not accounting for transfers to the sellers, which are sunk) is:

$$
\Pi^{B}\left(R_{1}, 0\right)-C\left(R_{1}\right)-C\left(R_{2}\right)
$$

Profits can always be improved by setting $R_{2}=0 \mathrm{~s}$, contradicting the optimality assumption. Thus any development such as $R_{1} \geq R_{2}>0$ cannot be optimal and optimal development requires setting the level of development of one of the two resources at zero. Define $R^{H * *}$ the high (non-zero) level of development and $R^{L * *}=0$ the low level of development.

(iii) Proof of $R^{H * *}>R^{I D}$. From (i) we know that the objective function of the buyer developing without competition is equal to $\Pi^{B}\left(R_{i}, 0\right)-C\left(R_{i}\right)$. The objective function of a buyer developing non-cooperatively is $\Pi^{B}\left(R_{i}, R_{-i}\right)-C\left(R_{i}\right)$ with $R_{-i}>0$. But $\frac{\partial \Pi^{B}\left(R_{i}, 0\right)}{\partial R_{i}}>\frac{\partial \Pi^{B}\left(R_{i}, R_{-i}\right)}{\partial R_{i}}$ and thus the optimal development level $R^{H * *}$ is always higher than that of a buyer developing under competition.

Proof of $R^{A d d * *} \geq R^{I D}$ if $\partial^{2} \Pi^{B}(x, y) / \partial x^{2} \geq 0$. If there are increasing returns to having a higher quality combined resource $\left(\partial^{2} \Pi^{B}(x, y) / \partial x^{2} \geq 0\right)$ then developing one resource increases the returns to developing the other. The outcome is that each resource is more developed.

Proof of $R^{A d d * *} \geq R^{A d d i t i v e}$. Define $R^{0}$ the development level that maximizes profits of a supplier in the baseline supplier development game when the other supplier does not develop. By definition, $R^{0}$ maximizes:

$$
\Pi^{B}(R, 0)-\Pi^{B}(0, R)-C(R)
$$

Because of strategic substitutability of that game, we have $R^{0}>R^{\text {Additive }}$. Now, we look into the conditions that lead to $R^{A d d * *}$ and $R^{0}$. Due to (i) above, $R^{A d d * *}$ maximizes $\Pi^{B}(2 R, 0)-2 C(R)$ or, equivalently,

$$
\frac{1}{2} \Pi^{B}(2 R, 0)-C(R)
$$

By the strict convexity of the first argument of $\Pi^{B}$ we have:

$$
\frac{\partial}{\partial R}\left[\frac{1}{2} \Pi^{B}(2 R, 0)\right]>\frac{\partial \Pi^{B}(R, 0)}{\partial R},
$$

while $-\frac{\partial \Pi^{B}(0, R)}{\partial R}>0$. Thus, if the absolute value of $\frac{\partial \Pi^{B}(0, R)}{\partial R}$ is small enough relative to $\frac{\partial \Pi^{B}(R, 0)}{\partial R}$ for all 
$R$, then $R^{A d d * *}$, the maximizer of (9), is always more than $R^{0}$, the maximizer of (8). And thus, $R^{\text {Add** }}>$ $R^{\text {Additive }}$.

Proof of $R^{H * *}>R^{H}$. By definition, $R^{H}$ is the $R$ that maximizes $\Pi^{B}\left(R, R^{L}\right)-\Pi^{B}(0, R)-C(R)$ while $R^{H * *}$ maximizes $\Pi^{B}(R, 0)-C(R)$. We have $\partial \Pi^{B}\left(R, R^{L}\right) / \partial R<\partial \Pi^{B}(R, 0) / \partial R$. By a similar argument as above, $R^{H * *}$ will be more than $R^{H}$ whenever $\frac{\partial \Pi^{B}(0, R)}{\partial R}$ is small relative to $\frac{\partial \Pi^{B}(R, 0)}{\partial R}$ for all $R$.

\section{Proof of Proposition 4}

The proof closely follows the proof of Proposition 1 and is omitted.

\section{Proof of Proposition 5}

Let:

$$
\underbrace{\frac{\partial^{2} \Pi^{B}\left(R_{i}+R^{\text {Additive }}, 0, \theta\right)}{\partial \theta \partial R_{i}}}_{\text {Use value }} \underbrace{\frac{\partial^{2} \Pi^{B}\left(R^{\text {Additive }}, R_{i}, \theta\right)}{\partial \theta \partial R_{i}}}_{\text {Preemption value }}>0 \text {, at }\left(R^{\text {Additive }}, \theta_{0}\right),
$$

and,

$$
\frac{\partial^{2} \Pi^{B}\left(R_{i}, R^{I D}, \theta\right)}{\partial \theta \partial R_{i}}<0, \text { at }\left(R^{I D}, \theta_{0}\right)
$$

If inequality (10) is satisfied, then the objective function of a seller exhibits increasing differences in its action $R_{i}$ and $\theta$. This implies by the principle of monotone comparative statics that the best response of the seller moves up. By symmetry of the game, this implies that the symmetric pure strategy equilibrium $R^{\text {Additive }}$ is increasing. The same reasoning applies to the development level when sellers contract with buyers the terms of the development.

The same reasoning is used to show the other points. Inequality (11), if satisfied, implies decreasing differences, entailing a lower equilibrium development level $R^{I D}$. Both inequalities (10) and (11) can be satisfied at the same time given the assumptions.

\section{Proof of Proposition 6}

Let:

$$
\begin{array}{r}
\frac{\partial^{2} \Pi^{B}\left(R_{i}, R^{H}, \theta\right)}{\partial \theta \partial R_{i}}<0, \text { at }\left(R^{L}, \theta_{0}\right), \\
\frac{\partial^{2} \Pi^{B}\left(R_{i}, R^{L}, \theta\right)}{\partial \theta \partial R_{i}}-\frac{\partial^{2} \Pi^{B}\left(0, R_{i}, \theta\right)}{\partial \theta \partial R_{i}}>0, \text { at }\left(R^{H}, \theta_{0}\right) .
\end{array}
$$

If both inequalities (12) and (13) are satisfied at the same time, then the best response of the high level developer increases, while that of the low level developer decreases thanks respectively to increasing and decreasing differences in own action $R_{i}$ and $\theta$. Since we have strategic substitutes in development levels, the indirect strategic effect goes in the same direction as the direct effect.

\section{APPENDiX B: AlternAtive STRATEGIC FACTOR MARKET MODEL}

In the base model resource suppliers sell their resources simultaneously. However, in actual factor markets, sales may not be perfectly simultaneous. Are the results from the simultaneous sale model robust if sales are sequential but suppliers do not know in advance the order in which the sales proceed? To answer this question, this appendix analyzes a model where sales in the factor market are sequential, but the order of the sales is randomly determined. In this alternative to the base model, the timing is as follows:

1. Sellers make their development decisions simultaneously.

2. The order of sale is randomly determined. With probability $1 / 2$, seller $S_{1}$ is designated the first seller 
$\left(S_{F}\right)$ and $S_{2}$ the second seller $\left(S_{S}\right)$. With probability $1 / 2, S_{1}$ is designated second seller $\left(S_{S}\right)$ and $S_{2}$ first seller $\left(S_{F}\right)$.

3. Seller $S_{F}$ enters the factor market and sells its resource in a second price auction. The buyers submit bids. If bids are identical, the resource is randomly allocated to one of the two buyers (with each buyer having a strictly positive probability of winning).

4. Seller $S_{S}$ enters the factor market and puts its resource to sale in a second price auction. If bids are identical, the resource is randomly allocated to one of the two buyers (with each buyer having a strictly positive probability of winning).

5. Buyers compete in the product market.

We use backward induction to find a subgame perfect Nash equilibrium. Fix the development levels of the resources sold by Seller $S_{F}$ and $S_{S}$ at $R_{F}$ and $R_{S}$ respectively. For the factor market, we have the following possible outcomes:

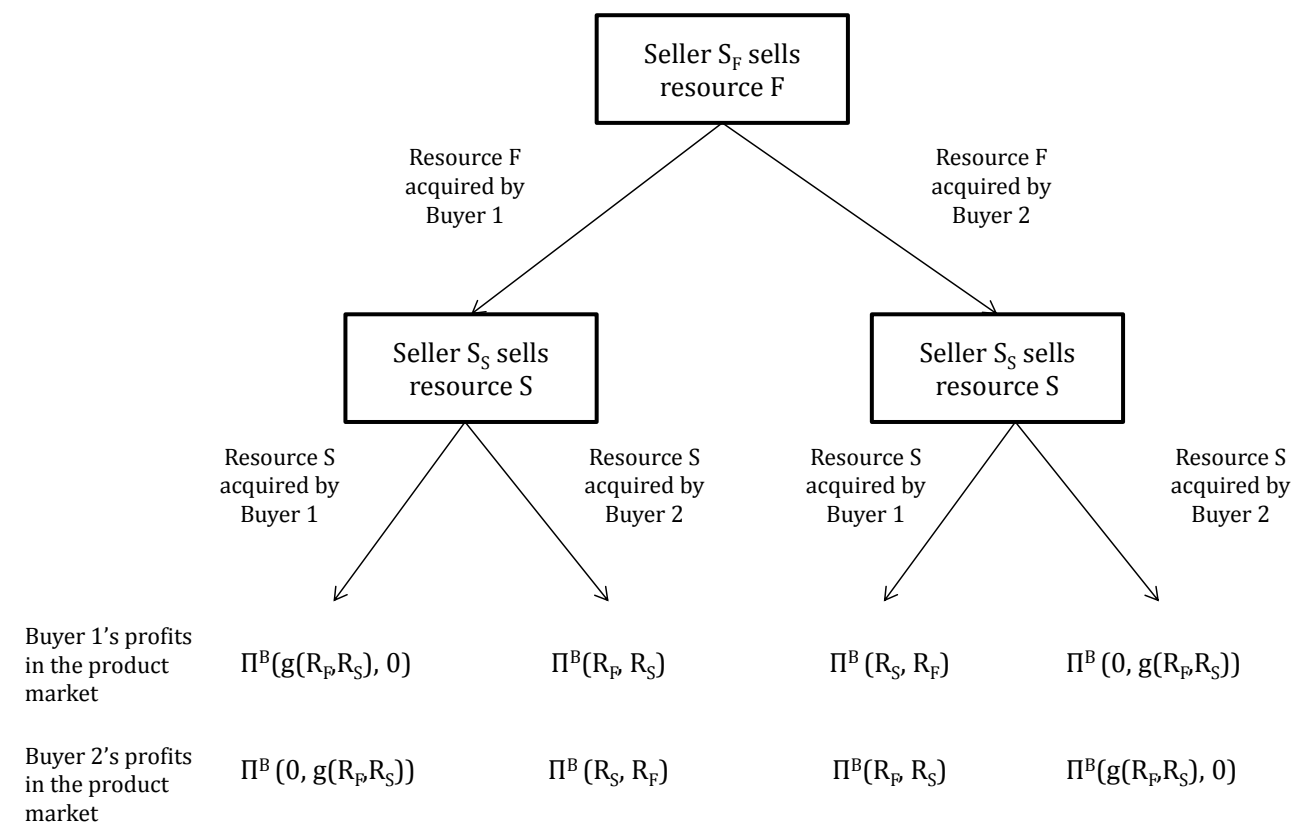

Figure 2: Sequential sales and product market outcomes

\section{Sale of resource $R_{S}$}

Without loss of generality, assume that resource $\mathrm{F}$ was acquired by buyer $B_{1}$. Then the bids for resource $\mathrm{S}$ are respectively:

$$
b i d_{B_{1}}^{S}=\Pi^{B}\left(g\left(R_{F}+R_{S}\right), 0\right)-\Pi^{B}\left(R_{F}, R_{S}\right), \quad b i d_{B_{2}}^{S}=\Pi^{B}\left(R_{S}, R_{F}\right)-\Pi^{B}\left(0, g\left(R_{F}+R_{S}\right)\right) .
$$

If $b i d_{B_{1}}^{S}>b i d_{B_{2}}^{S}$ then buyer $B_{1}$ outbids buyer $B_{2}$. This is the case if:

$$
\Pi^{B}\left(g\left(R_{F}+R_{S}\right), 0\right)-\Pi^{B}\left(R_{F}, R_{S}\right)>\Pi^{B}\left(R_{S}, R_{F}\right)-\Pi^{B}\left(0, g\left(R_{F}+R_{S}\right)\right) .
$$


Condition (14) is the same as inequality (1) in the body of the paper - only the labels of the resources are different (1 and 2 vs. S and F).

We can make the same analysis in the other branch of the tree, where resource $\mathrm{F}$ was acquired by buyer $B_{2}$ in the first sale. Again, if inequality (14) holds, we find that resource $S$ is bought by the buyer who previously bought resource $\mathrm{F}$. In that case, as this is a second price auction, the price paid for resource $\mathrm{S}$ is the bid of the losing bidder:

$$
p_{S}\left(R_{F}, R_{S}\right)=\Pi^{B}\left(R_{S}, R_{F}\right)-\Pi^{B}\left(0, g\left(R_{F}, R_{S}\right)\right) .
$$

If inequality (14) does not hold, then resource $\mathrm{S}$ is bought by the buyer who did not buy resource F. The transaction price is then:

$$
p_{S}\left(R_{F}, R_{S}\right)=\Pi^{B}\left(g\left(R_{F}, R_{S}\right), 0\right)-\Pi^{B}\left(R_{F}, R_{S}\right) .
$$

Since (14) is equivalent to (1), we have:

Proposition 7 For any given level of resource development, the eventual allocation of resources to buyers in the alternative strategic factor market is identical to that of the base model.

Sale of resource $R_{F}$

Moving up to the sale of resource F, consider first the case where inequality (14) holds. As shown above, whoever buys resource $\mathrm{F}$ will also necessarily buy resource $\mathrm{S}$. Each potential buyer then bids an amount equal to the profits from owning the two resources versus the alternative of owning no resource $\left(\Pi^{B}\left(g\left(R_{F}+\right.\right.\right.$ $\left.\left.\left.R_{S}\right), 0\right)-\Pi^{B}\left(0, g\left(R_{F}, R_{S}\right)\right)\right)$, minus the cost of acquiring the second resource $\left(p_{S}\left(R_{F}, R_{S}\right)\right)$ in the second sale. Thus:

$$
\begin{aligned}
\operatorname{bid} d_{B_{1}}^{F}=b i d_{B_{2}}^{F} & =\Pi^{B}\left(g\left(R_{F}, R_{S}\right), 0\right)-\Pi^{B}\left(0, g\left(R_{F}, R_{S}\right)\right)-\underbrace{\left[\Pi^{B}\left(R_{S}, R_{F}\right)+\Pi^{B}\left(0, g\left(R_{F}, R_{S}\right)\right)\right]}_{p_{S}\left(R_{F}, R_{S}\right)} \\
& =\Pi^{B}\left(g\left(R_{F}, R_{S}\right), 0\right)-\Pi^{B}\left(R_{S}, R_{F}\right) .
\end{aligned}
$$

Since buyers value the resources similarly the bids are tied, and the winner of the auction of the first resource is randomly chosen.

In the case where inequality (14) does not hold, whoever buys resource F will necessarily not buy resource $\mathrm{S}$. Each potential buyer then bids an amount equal to the profits from owning resource $\mathrm{F}$ versus the alternative, which is owning resource $\mathrm{S}\left(\Pi^{B}\left(R_{F}, R_{S}\right)-\Pi\left(R_{S}, R_{F}\right)\right)$ minus the cost of acquiring resource $\mathrm{S}$ $\left(p_{S}\left(R_{F}, R_{S}\right)\right)$. Thus:

$$
\begin{aligned}
b i d_{B_{1}}^{F}=b i d_{B_{2}}^{F} & =\Pi^{B}\left(R_{F}, R_{S}\right)-\Pi\left(R_{S}, R_{F}\right)-\underbrace{\left[\Pi^{B}\left(g\left(R_{F}, R_{S}\right), 0\right)-\Pi^{B}\left(R_{F}, R_{S}\right)\right]}_{p_{S}\left(R_{F}, R_{S}\right)} \\
& =\Pi^{B}\left(g\left(R_{F}, R_{S}\right), 0\right)-\Pi\left(R_{S}, R_{F}\right) .
\end{aligned}
$$

\section{Expected revenues by sellers of resources}

To sum up our results so far, if inequality (14) holds, one randomly determined buyer buys both resources at prices:

$$
\begin{aligned}
p_{F}\left(R_{F}, R_{S}\right) & =\Pi^{B}\left(g\left(R_{F}, R_{S}\right), 0\right)-\Pi^{B}\left(R_{S}, R_{F}\right), \\
p_{S}\left(R_{1}, R_{2}\right) & =\Pi^{B}\left(R_{S}, R_{F}\right)-\Pi^{B}\left(0, g\left(R_{F}, R_{S}\right)\right) .
\end{aligned}
$$


If instead inequality (14) does not hold, one randomly determined buyer buys resource 1 and the other resource 2. The prices are then:

$$
\begin{gathered}
p_{F}\left(R_{F}, R_{S}\right)=\Pi^{B}\left(g\left(R_{F}, R_{S}\right), 0\right)-\Pi^{B}\left(R_{S}, R_{F}\right), \\
p_{S}\left(R_{F}, R_{S}\right)=\Pi^{B}\left(g\left(R_{F}, R_{S}\right), 0\right)-\Pi^{B}\left(R_{F}, R_{S}\right) .
\end{gathered}
$$

We can calculate the expected revenues in each of these cases: seller $S_{i}$ expects to be the first $\left(S_{F}\right)$ to sell with probability $1 / 2$, and to be second to sell $\left(S_{S}\right)$ with probability $1 / 2$.

Case 1: Assume (14) holds

If inequality (14) holds, seller's $S_{i}$ expected revenues are thus:

$$
R e v_{A l t}^{i}=\frac{1}{2}\left[\Pi^{B}\left(g\left(R_{i}, R_{-i}\right), 0\right)-\Pi^{B}\left(R_{-i}, R_{i}\right)+\Pi^{B}\left(R_{i}, R_{-i}\right)-\Pi^{B}\left(0, g\left(R_{i}, R_{-i}\right)\right)\right] .
$$

By contrast, in the main model (see proposition 2), the revenues of seller $S_{i}$ are:

$$
\operatorname{Rev} v_{\text {Base }}^{i}=\Pi^{B}\left(R_{i}, R_{-i}\right)-\Pi^{B}\left(0, g\left(R_{i}, R_{-i}\right)\right) .
$$

We have:

$$
\begin{aligned}
R e v_{\text {Alt }}^{i}-\operatorname{Rev}_{\text {Base }}^{i}= & \frac{1}{2}\left[\Pi^{B}\left(g\left(R_{i}, R_{-i}\right), 0\right)-\Pi^{B}\left(R_{-i}, R_{i}\right)+\Pi^{B}\left(R_{i}, R_{-i}\right)-\Pi^{B}\left(0, g\left(R_{i}, R_{-i}\right)\right)\right] \\
& \quad-\Pi^{B}\left(R_{i}, R_{-i}\right)+\Pi^{B}\left(0, g\left(R_{i}, R_{-i}\right)\right) \\
= & \frac{1}{2}\left[\Pi^{B}\left(g\left(R_{i}, R_{-i}\right), 0\right)+\Pi^{B}\left(0, g\left(R_{i}, R_{-i}\right)\right)-\Pi^{B}\left(R_{-i}, R_{i}\right)-\Pi^{B}\left(R_{i}, R_{-i}\right)\right] \\
> & 0 .
\end{aligned}
$$

The last inequality is satisfied by assumption as it is simply half of (14). This establishes that expected revenues in the alternative model are always strictly higher as in the base model in this case.

\section{Case 2: Assume (14) does not hold}

If inequality (14) does not hold, seller's $S_{i}$ expected revenues are thus:

$$
\begin{aligned}
R e v_{A l t}^{i} & =\frac{1}{2}\left[\Pi^{B}\left(g\left(R_{i}, R_{-i}\right), 0\right)-\Pi^{B}\left(R_{-i}, R_{i}\right)\right]+\frac{1}{2}\left[\Pi^{B}\left(g\left(R_{i}, R_{-i}\right), 0\right)-\Pi^{B}\left(R_{-i}, R_{i}\right)\right] \\
& =\Pi^{B}\left(g\left(R_{i}, R_{-i}\right), 0\right)-\Pi^{B}\left(R_{-i}, R_{i}\right) .
\end{aligned}
$$

But the revenues in that case, in the main model are (see proposition 2):

$$
\operatorname{Rev}_{\text {Base }}^{i}=\Pi^{B}\left(g\left(R_{i}, R_{-i}\right), 0\right)-\Pi^{B}\left(R_{-i}, R_{i}\right) .
$$

Thus, if inequality (14) does not hold, $R e v_{A l t}^{i}=\operatorname{Rev}_{\text {Base }}^{i}$.

We can conclude from this analysis:

Proposition 8 For given levels of resource development, expected seller revenues are at least as high in the alternative model than in the base model.

\section{Equilibrium development levels in the alternative model relative to the base model}

In this section we compare the equilibrium development levels (under competition) in stage 1 of the alternative game to those in the base model. The analytical approach uses the principle of monotone comparative statics (Topkis, 1998) applied to supermodular games (Vives, 1999) in a similar manner as in the proof of Proposition 
2. The profit functions of the suppliers can be written as:

$$
\Pi_{i}^{S}=\operatorname{Rev}_{\text {Base }}^{i}+\mathbf{1}_{\text {Alt }} \cdot\left[\operatorname{Rev}_{\text {Alt }}^{i}-\operatorname{Rev}_{\text {Base }}^{i}\right]-C\left(R_{i}\right), \quad i \in\{1,2\} .
$$

If $\mathbf{1}_{A l t}=0$, we have the base game. If $\mathbf{1}_{A l t}=1$, we have the alternative game. We can use the tools developed by Topkis (1998: 183) and Vives (1999) to compare the Nash equilibria of these two games. Specifically, if $\frac{\partial}{\partial R_{i}}\left(\operatorname{Rev}_{A l t}^{i}-\operatorname{Rev}_{\text {Base }}^{i}\right) \geq 0$ then best responses in the alternative game for both suppliers will be larger than in the base game. We now find sufficient conditions that guarantee this.

Case 1: Assume (14) holds

We have, in the general case:

$$
\frac{\partial\left(\operatorname{Rev}_{A l t}^{i}-\operatorname{Rev}_{\text {Base }}^{i}\right)}{\partial R_{i}}=\frac{1}{2}\left[\frac{\partial \Pi^{B}\left(g\left(R_{i}, R_{-i}\right), 0\right)}{\partial R_{i}}-\frac{\partial \Pi^{B}\left(R_{i}, R_{-i}\right)}{\partial R_{i}}+\frac{\partial \Pi^{B}\left(0, g\left(R_{i}, R_{-i}\right)\right)}{\partial R_{i}}-\frac{\partial \Pi^{B}\left(R_{-i}, R_{i}\right)}{\partial R_{i}}\right] .
$$

Additive case Consider now the additive case (i.e., when $g(x, y)=x+y$ ). In this case, we have:

$$
\frac{\partial\left(\operatorname{Rev}_{A l t}^{i}-\operatorname{Rev}_{\text {Base }}^{i}\right)}{\partial R_{i}}=\frac{1}{2}\left[\frac{\partial \Pi^{B}\left(R_{i}+R_{-i}, 0\right)}{\partial R_{i}}-\frac{\partial \Pi^{B}\left(R_{i}, R_{-i}\right)}{\partial R_{i}}+\frac{\partial \Pi^{B}\left(0, R_{i}+R_{-i}\right)}{\partial R_{i}}-\frac{\partial \Pi^{B}\left(R_{-i}, R_{i}\right)}{\partial R_{i}}\right] .
$$

We now show that a sufficient condition for $\frac{\partial}{\partial R_{i}}\left(\operatorname{Rev}_{A l t}^{i}-\operatorname{Rev}_{I D}^{i}\right) \geq 0$ is the convexity of $\Pi^{B}(x, y)$ in both its arguments. Indeed, on the one hand, we have:

$$
\frac{\partial \Pi^{B}\left(R_{i}+R_{-i}, 0\right)}{\partial R_{i}} \geq \frac{\partial \Pi^{B}\left(R_{i}+R_{-i}, R_{-i}\right)}{\partial R_{i}} \geq \frac{\partial \Pi\left(R_{i}, R_{-i}\right)}{\partial R_{i}} .
$$

The first inequality follows from the decreasing marginal returns of $\Pi^{B}$ (since $\partial^{2} \Pi^{B}(x, y) / \partial x \partial y<0$ and $\left.R_{-i} \geq 0\right)$, the second is due to the convexity of the first argument of $\Pi\left(\partial^{2} \Pi(x, y) / \partial x^{2}>0\right)$. Thus:

$$
\frac{\partial \Pi^{B}\left(R_{i}+R_{-i}, 0\right)}{\partial R_{i}}-\frac{\partial \Pi\left(R_{i}, R_{-i}\right)}{\partial R_{i}} \geq 0
$$

On the other hand, we have:

$$
\frac{\partial \Pi\left(0, R_{i}+R_{-i}\right)}{\partial R_{i}} \geq \frac{\partial \Pi^{B}\left(0, R_{i}\right)}{\partial R_{i}} \geq \frac{\partial \Pi^{B}\left(R_{-i}, R_{i}\right)}{\partial R_{i}} .
$$

The first inequality follows from the convexity of the second argument of $\Pi^{B}\left(\partial^{2} \Pi(x, y) / \partial y^{2}>0\right)$, the second is due to the decreasing marginal returns of $\Pi^{B}$ (i.e., $\partial^{2} \Pi^{B}(x, y) / \partial x \partial y<0$ and $R_{i} \geq 0$ ). Thus:

$$
\frac{\partial \Pi\left(0, R_{i}+R_{-i}\right)}{\partial R_{i}}-\frac{\partial \Pi^{B}\left(R_{-i}, R_{i}\right)}{\partial R_{i}} \geq 0
$$

Taking (15) and (16) together implies $\frac{\partial}{\partial R_{i}}\left(\operatorname{Rev}_{\text {Alt }}^{i}-\operatorname{Rev}_{\text {Base }}^{i}\right) \geq 0$ in the additive case. Consequently, following the principle of monotone comparative static, symmetric Nash equilibrium development levels in the additive version of the alternative game will be superior to those of the base game. That is, denoting $\left(R^{\text {Additive-Alt }}, R^{\text {Additive-Alt }}\right)$ the Nash equilibrium of the alternative game, we have: $R^{\text {Additive-Alt }} \geq$ $R^{\text {Additive }}$. 
Exclusive case In the exclusive case, if $R_{i} \geq R_{-i}$, we have, due to the decreasing marginal returns of $\Pi^{B}$ (i.e., $\partial^{2} \Pi^{B}(x, y) / \partial x \partial y<0$ :

$$
\frac{\partial\left(\operatorname{Rev}_{\text {Alt }}^{i}-\operatorname{Rev}_{\text {Base }}^{i}\right)}{\partial R_{i}}=\frac{1}{2}\left[\frac{\partial \Pi^{B}\left(R_{i}, 0\right)}{\partial R_{i}}-\frac{\partial \Pi^{B}\left(R_{i}, R_{-i}\right)}{\partial R_{i}}+\frac{\partial \Pi^{B}\left(0, R_{i}\right)}{\partial R_{i}}-\frac{\partial \Pi^{B}\left(R_{-i}, R_{i}\right)}{\partial R_{i}}\right] \geq 0 .
$$

This means that returns to development are always higher in the alternative model than in the base model for the agent who develops more than the competitor.

If $R_{i}<R_{-i}$, we have instead:

$$
\begin{aligned}
\frac{\partial\left(R e v_{A l t}^{i}-R e v_{\text {Base }}^{i}\right)}{\partial R_{i}} & =\frac{1}{2}\left[\frac{\partial \Pi^{B}(0,0)}{\partial R_{i}}-\frac{\partial \Pi^{B}\left(R_{i}, R_{-i}\right)}{\partial R_{i}}+\frac{\partial \Pi^{B}(0,0)}{\partial R_{i}}-\frac{\partial \Pi^{B}\left(R_{-i}, R_{i}\right)}{\partial R_{i}}\right] \\
& =\frac{1}{2}\left[-\frac{\partial \Pi^{B}\left(R_{i}, R_{-i}\right)}{\partial R_{i}}-\frac{\partial \Pi^{B}\left(R_{-i}, R_{i}\right)}{\partial R_{i}}\right]
\end{aligned}
$$

Recall that $\partial \Pi^{B} x, y / \partial x>0$ while $\partial \Pi^{B} x, y / \partial y<0$. Thus a sufficient condition to ensure that the expression above is negative is:

$$
\left|\frac{\partial \Pi^{B}(x, y)}{\partial x}\right| \geq\left|\frac{\partial \Pi^{B}(x, y)}{\partial y}\right| .
$$

This condition means that a marginal increase in one's resource level has more absolute effect effect than a marginal increase in the competitor's resource level.

With this assumption, because $\Pi^{B}$ exhibits decreasing differences (i.e., strategic substitutes), this is enough to ensure that results in the base model still hold in the alternative model. Indeed, following the structure of the proof of Proposition 2 in the base model we can shwo that in the alternative model the firm developing at a high level would develop at an even higher level while the firm developing at a low level would develop at an even lower level.

We thus have:

Proposition 9 Assume inequality (14) holds.

- If resources are additive, and $\Pi^{B}$ is convex in both arguments, then symmetric development levels are at least as high as in the base model. That is, denoting $\left(R^{\text {Additive } \mid \text { Alt }}, R^{\text {Additive|Alt }}\right)$ the Nash equilibrium of the alternative game, we have: $R^{\text {Additive } \mid \text { Alt }} \geq R^{\text {Additive }}$.

If resources are exclusive, and a marginal increase in one's resource level has more absolute effect effect than a marginal increase in the competitor's resource level, pure strategy development Nash equilibria are asymmetric. Moreover, the high level of development in the alternative model is higher than the high level of development in the base model, while the low level of development in the alternative model is lower than the low level of development in the base model. That is, development levels in any asymmetric Nash equilibrium of the alternative game take the values $R^{H \mid \text { Alt }}$ and $R^{L \mid A l t}$ and we have $R^{H \mid A l t} \geq R^{H}$ and $R^{L \mid A l t} \leq R^{L}$

The assumption that $\Pi^{B}$ is convex in both arguments is a weak one. It is satisfied in most models of product market competition where resources allow for improvement of quality or reduction of cost, including those in which our assumption that resources are strategic substitutes holds as well (Athey and Schmutzler, 2001).

Similarly, the assumption that a marginal increase in one's resource level has more absolute effect effect than a marginal increase in the competitor's resource level is intuitive.

Case 2: Assume (14) does not holds

As seen above, if inequality (14) does not hold, the revenues are identical to those in the base model (i.e., $R e v_{A l t}^{i}-\operatorname{Rev}_{\text {Base }}^{i}=0$ ), and thus all results in the main body of the paper hold as they are. 
Proposition 10 Assume inequality (14) does not hold. The alternative and the base model are identical.

Summary of findings

In summary:

- If (14) does not hold: results in the alternative model are exactly the same as in the base model.

- If (14) holds and resources are additive, we only need the additional assumption of convex first component of $\Pi$ to guarantee at least as strong results in the alternative model as in the base model. This assumption is verified in all basic IO models.

- If (14) holds and resources are exclusive, we only need the additional assumption that deploying a resource for oneself has a higher absolute effect on profits than deployment by a competitor.

The sufficient conditions that guarantee stronger development levels in the alternative model compared to the base model are weak, as they are intuitive and will be verified in most applications of interest to strategy research. Moreover, these conditions are merely sufficient. This means that both the base and the alternative model share similar broad characteristics. Using one or the other model will not lead to qualitatively different conclusions except in some unusual cases.

\section{APPENDIX C: RESOURCE DEPLOYMENT AND PROFITS IN THE BERTRAND LIN- EAR DIFFERENTIATED MODEL}

Consider the following demand system where $\theta$ measures how the price set by a competitor affects a firm's demand:

$$
q_{1}=a-p_{1}+\theta p_{2}, \quad q_{2}=a-p_{2}+\theta p_{1} .
$$

Firm profits are given by:

$$
\Pi_{1}=\left(p_{1}-\left(c_{1}-R\right)\right) q_{1}, \quad \Pi_{1}=\left(p_{2}-c_{2}\right) q_{2} .
$$

where $R$ is a resource reducing marginal costs for firm 1. Firms compete in prices. Equilibrium prices and quantities are:

$$
p_{1}^{*}=\frac{2 a+\theta\left(a+c_{2}\right)+2\left(c_{1}-R\right)}{4-\theta^{2}}, \quad p_{2}^{*}=\frac{\left.2 a+\theta\left(a+c_{1}-R\right)+2 c_{2}\right)}{4-\theta^{2}}
$$

Profits are:

$$
\Pi_{1}=\frac{\left(2 a-2 c_{1}+R\left(2-\theta^{2}\right)+\theta\left(a+c_{2}\right)+\theta^{2} c_{1}\right)^{2}}{\left(4-\theta^{2}\right)^{2}} \quad \Pi_{2}=\frac{\left(2 a-2 c_{2}+\theta\left(a+c_{1}-R\right)+\theta^{2} c_{2}\right)^{2}}{\left(4-\theta^{2}\right)^{2}}
$$

We have:

$$
\begin{gathered}
\frac{\partial \Pi_{1}}{\partial R}=\frac{2\left(2-\theta^{2}\right)\left(a \theta+2 a+c_{1}\left(\theta^{2}-2\right)+c_{2} \theta+\theta^{2}(-R)+2 R\right)}{\left(4-\theta^{2}\right)^{2}}, \quad \frac{\partial^{2} \Pi_{1}}{\partial R^{2}}=\frac{2\left(\theta^{2}-2\right)^{2}}{\left(4-\theta^{2}\right)^{2}}>0 \\
\frac{\partial^{2} \Pi_{1}}{\partial \theta \partial R}=\frac{2\left(a \theta^{4}+4 a \theta^{3}+6 a \theta^{2}-8 a+8 c_{1}\left(\theta^{2}-2\right) \theta+c_{2}\left(\theta^{4}+6 \theta^{2}-8\right)-8 \theta^{3} R+16 \theta R\right)}{\left(4-\theta^{2}\right)^{3}}
\end{gathered}
$$

Let $a=4, \theta=0.95, c_{1}=c_{2}=0.2$. Then: $\frac{\partial \Pi_{1}}{\partial R}=2.69, \quad \frac{\partial^{2} \Pi_{1}}{\partial \theta \partial R}=-0.31<0$.

Let $a=4, \theta=0.50, c_{1}=c_{2}=0.2$. Then: $\frac{\partial \Pi_{1}}{\partial R}=2.41, \quad \frac{\partial^{2} \Pi_{1}}{\partial \theta \partial R}=1.00>0$. 